
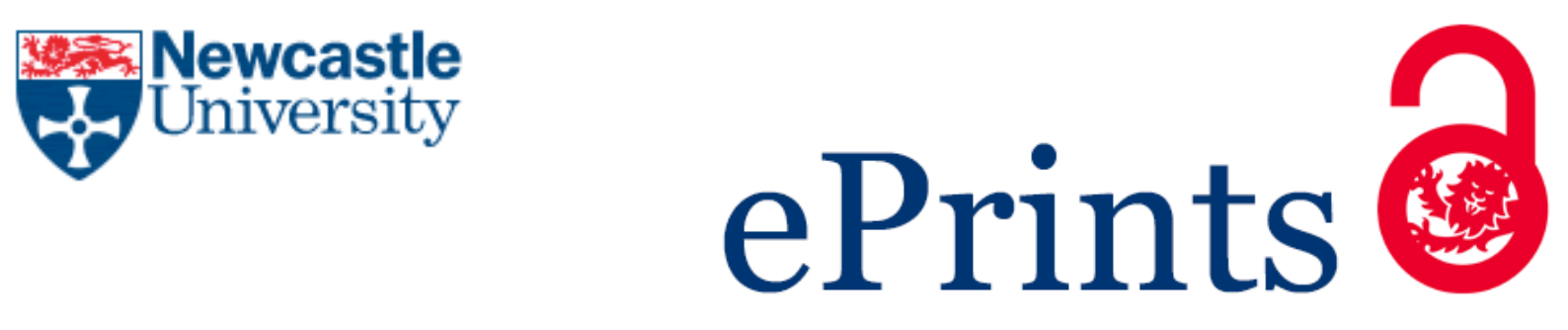

Moorthy V. Unique correlation between non-linear distortion of tangential magnetic field and magnetic excitation voltage - Unexplored ferromagnetic phenomena and their application for ferromagnetic materials evaluation. Journal of Magnetism and Magnetic Materials 2016, 398, 101-108.

Copyright:

(C) 2015. This manuscript version is made available under the CC-BY-NC-ND 4.0 license

DOI link to article:

http://dx.doi.org/10.1016/i.jmmm.2015.09.029

Date deposited:

$17 / 09 / 2015$

Embargo release date:

11 September 2017

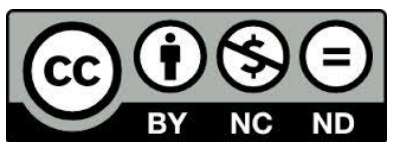

This work is licensed under a

Creative Commons Attribution-NonCommercial-NoDerivatives 4.0 International licence 
Final published version of this paper is available at http://dx.doi.org/10.1016/i.jmmm.2015.09.029

\title{
Unique Correlation between Non-linear Distortion of Tangential Magnetic Field and Magnetic Excitation Voltage - Unexplored Ferromagnetic Phenomena and their application for ferromagnetic materials evaluation
}

\author{
V. Moorthy \\ Design Unit, School of Mechanical and Systems Engineering, Newcastle University, \\ UK, v.moorthy@ncl.ac.uk
}

\begin{abstract}
Unexplored ferromagnetic phenomena of non-linear distortion of tangential magnetic field $\left(\mathrm{H}_{\mathrm{T}}\right)$ and that of excitation voltage $\left(V_{E}\right)$ across the electromagnetic $(E M)$ yoke, in the presence of a ferromagnetic material between the poles of the EM yoke, have been uniquely correlated in this study. Both the $\mathrm{H}_{T}$ and $\mathrm{V}_{E}$ show similar distortion behaviour, but in the opposite direction, with unique shape for each ferromagnetic sample with different microstructural conditions. Interestingly unique correlation between $\left(d V_{E} / d t\right)$ and $\left(d H_{T} / d t\right)$ profiles and their ability to distinguish different magnetisation behaviour of ferromagnetic material with different microstructures have also been discussed in this study. One to one correlation between the distortion of $\mathrm{H}_{T}$ and $\mathrm{V}_{E}$ shown in this study is clear evidence that both these parameters are strongly influenced by the same mechanism of magnetisation process, but in different ways. The systematic changes in the height and position of the peak and the trough on the time derivative profiles of $\mathrm{V}_{E}$ and $\mathrm{H}_{\mathrm{T}}$ reflect the subtle differences in the magnetisation process for each microstructural condition of the steel. This study reveals the new scientific insight and good potential of this novel as well as very simple approach of distortion analysis of $H_{T}$ and $V_{E}$ for understanding the influence of material properties on the mechanism of magnetisation process and also their suitability for variety of applications related to materials evaluation of ferromagnetic components and structures.
\end{abstract}

Key words: Non-linear distortion, tangential magnetic field, magnetic excitation voltage, ferromagnetism, microstructures, ferritic steel.

\section{Introduction}

Magnetic methods such as hysteresis loop (B-H loop) and magnetic Barkhausen noise (MBN) measurements are well known in the history of ferromagnetism and have been applied for the assessment of variations in the properties of ferromagnetic materials [1-8]. Several magnetic parameters such as coercive force, residual induction, permeability, MBN signal level etc. have been correlated to various material properties in ferritic steels. However, a common feature in all these magnetic measurements is the generation of cyclic applied magnetic field $\left(\mathrm{H}_{\mathrm{a}}\right)$ by applying an alternating bi-polar excitation voltage $\left(\mathrm{V}_{\mathrm{E}}\right)$ to a solenoid or a coil around an electromagnetic (EM) yoke. Generally in a quasi-static frequency triangular waveform magnetic excitation condition, the excitation voltage $\left(\mathrm{V}_{\mathrm{E}}\right)$ applied across the coil around the EM yoke is linearly related to the applied magnetic field strength $\left(\mathrm{H}_{\mathrm{a}}\right)$ measured at the centre of the air gap between the poles of an EM yoke (in open magnetic flux path circuit). But, in the presence of a different ferromagnetic material placed between the poles of the EM yoke (to achieve closed magnetic flux path circuit), both the $V_{E}$ and the tangential surface magnetic 
This article is author's version published in the Journal of Magnetism and Magnetic Materials, 398 (2016) 101-108.

Final published version of this paper is available at http://dx.doi.org/10.1016/i.jmmm.2015.09.029

field $\left(\mathrm{H}_{\mathrm{T}}\right)$ measured on the surface of the ferromagnetic material show non-linear distortion which is considered as an influence of magnetisation of the ferromagnetic sample introduced between the poles of the EM yoke [7-13]. Since the magnetisation process is strongly influenced by the microstructure and stresses in ferromagnetic materials, the non-linear distortion behaviour of $\mathrm{V}_{\mathrm{E}}$ and $\mathrm{H}_{\mathrm{T}}$ is expected to have some relationship and could distinguish subtle differences in the magnetisation process between different ferromagnetic materials.

Only recently, the non-linear distortion behaviour of $\mathrm{V}_{E}$ has been explored by the author based on the time derivative analysis $\left(d V_{E} / d t\right)$. The Distortion Analysis of Magnetic Excitation (DAME) voltage profile $\left(\left(d V_{E} / d t\right)\right.$ vs $\left.\mathrm{V}_{\mathrm{T}}\right)$ has been shown to uniquely identify different microstructural grades of a ferromagnetic material [9-10]. The non-linear distortion behaviour of $\mathrm{H}_{\mathrm{T}}$ had been shown earlier [7-8, 11-13] and the harmonic distortion factor derived from upper harmonics of $H_{T}$ has been correlated to magnetic properties [11,12]. However, the influence of material properties of the ferromagnetic samples on the non-linear distortion behaviour of tangential magnetic field $\left(\mathrm{H}_{T}\right)$ based on its time derivative analysis $\left(d H_{T} / d t\right)$ has not been widely explored previously to the best knowledge of the author in the literature. Stupakov [13] also showed only the effect of air gap on the distortion behaviour of $\mathrm{H}_{\mathrm{T}}$. This study is an extension of author's recent research to present the non-linear distortion behaviour of $\mathrm{H}_{T}$ and the direct correlation between the distortion behaviour of $\mathrm{V}_{E}$ and $\mathrm{H}_{\mathrm{T}}$. This paper attempts to show the unique correlation between the profiles of $\left(d V_{E} / d t\right)$ and $\left(d H_{T} / d t\right)$ and their potential to distinguish different microstructural grades of a ferritic steel using this novel and simple approach.

\section{Principle of distortion of tangential magnetic field}

It is known that the applied magnetic field $\left(\mathrm{H}_{\mathrm{a}}\right)$ at the centre of the $U$ shaped EM yoke can be measured only without any test sample between the poles of the yoke. In case of a triangular waveform magnetic excitation, the $\mathrm{H}_{\mathrm{a}}$ varies linearly with respect to the total voltage $\left(\mathrm{V}_{T}\right)$ applied to the EM yoke in a half cycle of magnetisation (from $-\mathrm{V}_{T \max }$ to $+\mathrm{V}_{T \max }$ ), that is from $\mathrm{H}_{\text {amax }}$ to $+\mathrm{H}_{\text {amax. }}$. However, in a full cycle, the plot of $\mathrm{H}_{\mathrm{a}}$ vs $\mathrm{V}_{\mathrm{T}}$ will show a small hysteresis loss depending on the characteristics of the core material of the EM yoke.

In the presence of any ferromagnetic sample between the poles of EM yoke, only tangential magnetic field $\left(\mathrm{H}_{T}\right)$ can be measured on the surface of sample. The variation in $\mathrm{H}_{T}$ is nonlinear and it strongly depends on the geometry and also on the properties of ferromagnetic material $[7,8]$. The $\mathrm{H}_{\mathrm{T}}$ can be considered as the effective magnetic field strength seen by the ferromagnetic test sample. Hence,

$$
\mathrm{H}_{\mathrm{T}}=\mathrm{H}_{\mathrm{a}}-\mathrm{H}_{\mathrm{d}}
$$

Where " $\mathrm{H}_{d}$ " is the demagnetising field which is related to the magnetisation of the sample by

$$
H_{d}=N_{d}^{*} M
$$

Where " $N_{d}$ " is the demagnetising factor and "M" is the magnetisation of the ferromagnetic sample. 
This article is author's version published in the Journal of Magnetism and Magnetic Materials, 398 (2016) 101-108.

Final published version of this paper is available at http://dx.doi.org/10.1016/i.jmmm.2015.09.029

In a solenoid type open loop magnetising circuit, the demagnetising effect will be quite large due to open magnetic flux path which will lead to reduced effective magnetising field strength in the sample resulting in shearing of the magnetic hysteresis loop. In case of electromagnetic yoke type closed loop magnetising circuit, the demagnetising effect will be smaller due to closed magnetic flux path. In addition, it is also known that the demagnetising factor, $\mathrm{N}_{\mathrm{d}}$, is a strong function of geometry and magnetisation of the ferromagnetic sample [14, 15]. For example, ferromagnetic sample with smaller length (I) to diameter (d) ratio will have larger demagnetising field which will reduce the effective magnetic field strength in the sample as compared to a sample with larger (I/d) ratio. The geometrical influence of external demagnetising field $\left(\mathrm{H}_{\mathrm{ed}}\right)$ is represented through the external demagnetising factor $\left(\mathrm{N}_{\mathrm{ed}}\right)$.

It has also been considered that the localised demagnetising field varies with interaction of magnetic domain walls with microstructural features in the ferromagnetic material [16-19]. Since the microstructural features such as grain boundaries, inclusions, second phase precipitates etc. are regions of discontinuity in the magnetisation vector and therefore associated with magnetic free poles. The distribution and density of magnetic free poles and hence the local magnetic energy are altered by the formation of new domains and the interaction of moving domain walls with these microstructural features. For example, the nucleation and growth of $180^{\circ}$-reverse spike domains or $90^{\circ}$-closure spike domains at the planar grain boundary interface reduce the surface magnetic pole density due to redistribution of magnetic free poles over larger area as shown in figure 1 and hence the reduction in localised magnetic free pole energy. Similarly, when the domain wall bi-sects an inclusion or second phase precipitate with or without closure domains, the localised magnetic energy is reduced due to redistribution of magnetic free poles of alternating sign on both sides of the domain wall as typically shown in figure 2 . Such variations in localised magnetic free pole energy would result in variation in the internal demagnetising field $\left(\mathrm{H}_{\mathrm{id}}\right)$ during the course of magnetisation process through the internal demagnetising factor $\left(\mathrm{N}_{\mathrm{id}}\right)$.
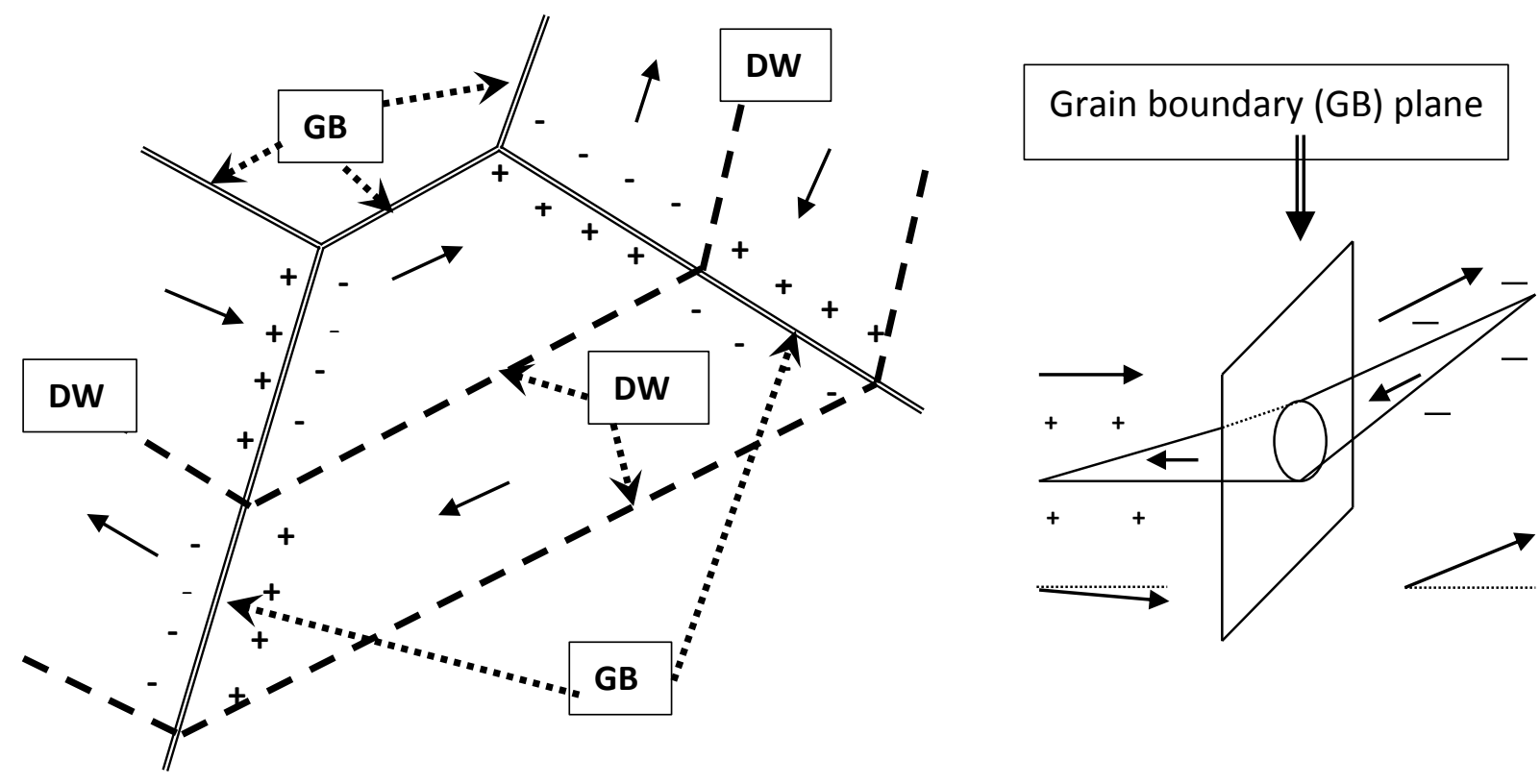
This article is author's version published in the Journal of Magnetism and Magnetic Materials, 398 (2016) 101-108.

Final published version of this paper is available at http://dx.doi.org/10.1016/i.jmmm.2015.09.029

(a)

(b)

Figure 1. (a) Multi-domain structure in a thermally demagnetized polycrystalline material with magnetic free poles at the grain boundary (GB) interface and (b) Schematic of formation of reverse spike domain structure at a grain boundary (GB) to reduce the boundary surface magnetic free pole density. (DW refers to Domain Wall).
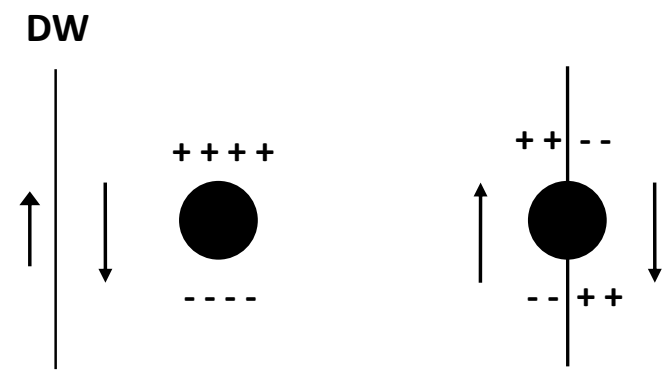

$$
\mathrm{H}_{\text {id }} \quad \mathrm{H}_{\mathrm{id}} / \mathbf{2}
$$

(a)

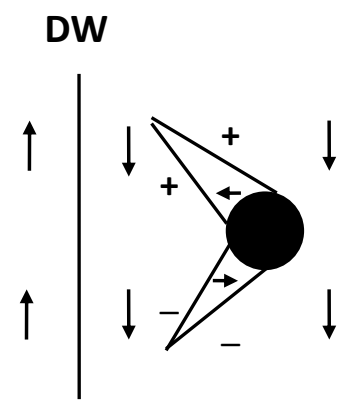

$H_{\text {id }}$

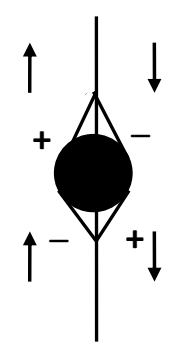

$\mathrm{H}_{\mathrm{id}} / \mathbf{2}$

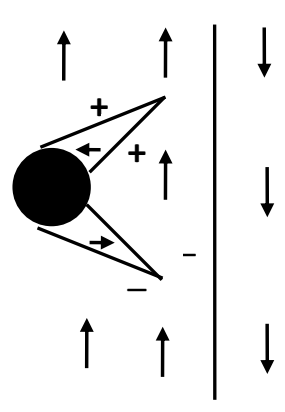

$H_{\text {id }}$

\section{Direction of magnetization}

(b)

Figure 2. Schematic of interaction of $180^{\circ}$ domain wall with inclusion / precipitate, (a) without closure domain and (b) with closure domain resulting in redistribution of magnetic free poles at the interface and hence reduction in internal demagnetizing field $\left(\mathrm{H}_{\mathrm{id}}\right)$. 
This article is author's version published in the Journal of Magnetism and Magnetic Materials, 398 (2016) 101-108.

Final published version of this paper is available at http://dx.doi.org/10.1016/i.jmmm.2015.09.029

Hence, the total demagnetising field, $\mathrm{H}_{d}$ can be written as

$$
\mathrm{H}_{\mathrm{d}}=\mathrm{H}_{\mathrm{ed}}+\mathrm{H}_{\mathrm{id}}
$$

Incorporating the influence of both external $\left(H_{e d}=N_{e d}{ }^{*} M_{e}\right)$ and internal $\left(H_{i d}=N_{i d}{ }^{*} M_{i}\right)$ demagnetising effects in equation (1), the $\mathrm{H}_{\mathrm{T}}$ becomes

$$
H_{T}=H_{a}-N_{e d}{ }^{*} M_{e}-N_{i d}{ }^{*} M_{i}
$$

where $M_{e}$ is the net magnetisation in the sample and $M_{i}$ is the localised spontaneous magnetisation near the microstructural features.

Considering the fact that the external demagnetising effect is minimum in a closed loop magnetic circuit having good contact (negligible air-gap) between the sample surface and the pole faces of the EM yoke, the $\mathrm{H}_{\mathrm{ed}}$ can be assumed to be small and constant for all test specimens with same geometry. Then, the variation in $\mathrm{H}_{T}$ can be considered to be mainly influenced by the effect of changing internal demagnetising $\left(\mathrm{H}_{\mathrm{id}}\right)$ effect caused by the localised variation in magnetostatic energy during the magnetisation process with a closed loop EM yoke. The variation in local magnetic energy is expected to contribute to the internal demagnetising $\left(\mathrm{H}_{\mathrm{id}}\right)$ effect during the entire magnetisation process, resulting in non-linear distortion in $\mathrm{H}_{\mathrm{T}}$. The strong influence of properties such as composition, microstructures and stresses on the magnetisation process is expected to influence the distortion of $H_{T}$ in a magnetisation cycle for ferromagnetic materials. Based on this fact, the applied magnetic field " $\mathrm{H}_{\mathrm{a}}$ " is a test material independent parameter whilst the tangential magnetic field " $\mathrm{H}_{\mathrm{T}}$ " is strongly a test material dependent parameter.

\section{Experimental procedure}

The schematic of the experimental set-up used to demonstrate the distortion of magnetic excitation voltage and tangential magnetic field is shown in figure 3 . The experimental details are exactly same as that mentioned elsewhere [9], except the additional measurement of magnetic field strength. The total applied excitation voltage $\left(V_{T}\right)$ of $\pm 20 \mathrm{~V}$ (at $\pm 1 \mathrm{~A}$ ) is applied across the coil wound around the EM yoke and a power resistor $\left(R_{C L}\right)$ connected in series. The magnetic field strength is measured using a Hall-effect sensor placed at the centre of the EM yoke. The Hall sensor voltage is linearly related to the magnetic field strength which is calibrated to give $\pm 20 \mathrm{mV}$ for $\pm 79.58 \mathrm{~A} / \mathrm{m}$. The applied magnetic field strength $\left(\mathrm{H}_{\mathrm{a}}\right)$ is measured in the air gap at the centre between the poles of EM yoke without any test specimen. The ironcored EM yoke generates a maximum applied magnetic field $\left(H_{a m a x}\right)$ of $\pm 20 \mathrm{kA} / \mathrm{m}$. The tangential magnetic field $\left(\mathrm{H}_{\mathrm{T}}\right)$ is measured on the surface of test sample at the centre of poles of EM yoke. The voltage signal across the excitation coil wound around the EM yoke $\left(\mathrm{V}_{\mathrm{E}}\right)$ and that of Hall sensor were passed through a $100 \mathrm{~Hz}$ low pass frequency filter to remove any high frequency noise in the signal. The $\mathrm{V}_{T}, \mathrm{~V}_{E}, \mathrm{H}_{\mathrm{a}}$ and $\mathrm{H}_{T}$ were acquired over 4 cycles of magnetisation with a total duration of $10 \mathrm{~s}$ at a sampling frequency of $200 \mathrm{kHz}$. The data is smoothened further by averaging with a time constant of $5 \mathrm{~ms}$ over 4 cycles of magnetisation. The $V_{E}, H_{a}$ and $H_{T}$ are plotted as a function of total applied excitation voltage $\left(V_{T}\right)$ as an 
This article is author's version published in the Journal of Magnetism and Magnetic Materials, 398 (2016) 101-108.

Final published version of this paper is available at http://dx.doi.org/10.1016/i.jmmm.2015.09.029

independent parameter on the $\mathrm{X}$-axis. The $\mathrm{V}_{\mathrm{E}}, \mathrm{H}_{\mathrm{a}}$ and $\mathrm{H}_{\mathrm{T}}$ are also differentiated with $d t$ of 1 ms to obtain $\left(d V_{E} / d t\right), \quad\left(d H_{a} / d t\right)$ and $\left(d H_{T} / d t\right)$ profiles and are plotted as a function of $\mathrm{V}_{\mathrm{T}}$ for further analysis of the profiles.

The $18 \mathrm{CrNiMo5}$ ferritic steel rectangular bar samples used in this study are same as those used earlier and the details of different heat-treatments and microstructural conditions (ARAs-Rolled, IA-Isothermally Annealed, SPA- Spheroidising Annealed and QT- Quenched and Tempered) are reported earlier [9]. For this study, the effect of external demagnetising field is kept almost constant and at minimum by keeping two factors more or less uniform. The sample dimension (70 $\mathrm{mm} \times 20 \mathrm{~mm} \times 5 \mathrm{~mm}$ ) is kept constant to an accuracy of $\pm 0.1 \mathrm{~mm}$ for all the samples. The sample surfaces and the pole faces of the EM yoke have good abrasive wheel cutting / machining finish with surface roughness better than $10 \mu \mathrm{m}$. The samples are magnetised along the wider face with the flat surface pole faces of the EM yoke legs which ensures good surface contact between the sample and the pole faces of the EM yoke. With parallel surface contact between the sample and the yoke, any air gap will be minimum and limited by the inherent surface roughness factor and hence the minimum external demagnetising field $\left(\mathrm{H}_{\mathrm{ed}}\right)$. However in practice, better control in the accuracy of sample geometry and the effectiveness of magnetic contact between the sample and the EM yoke will definitely enhance the repeatability of the measurement and the correlation with changes in the material properties.

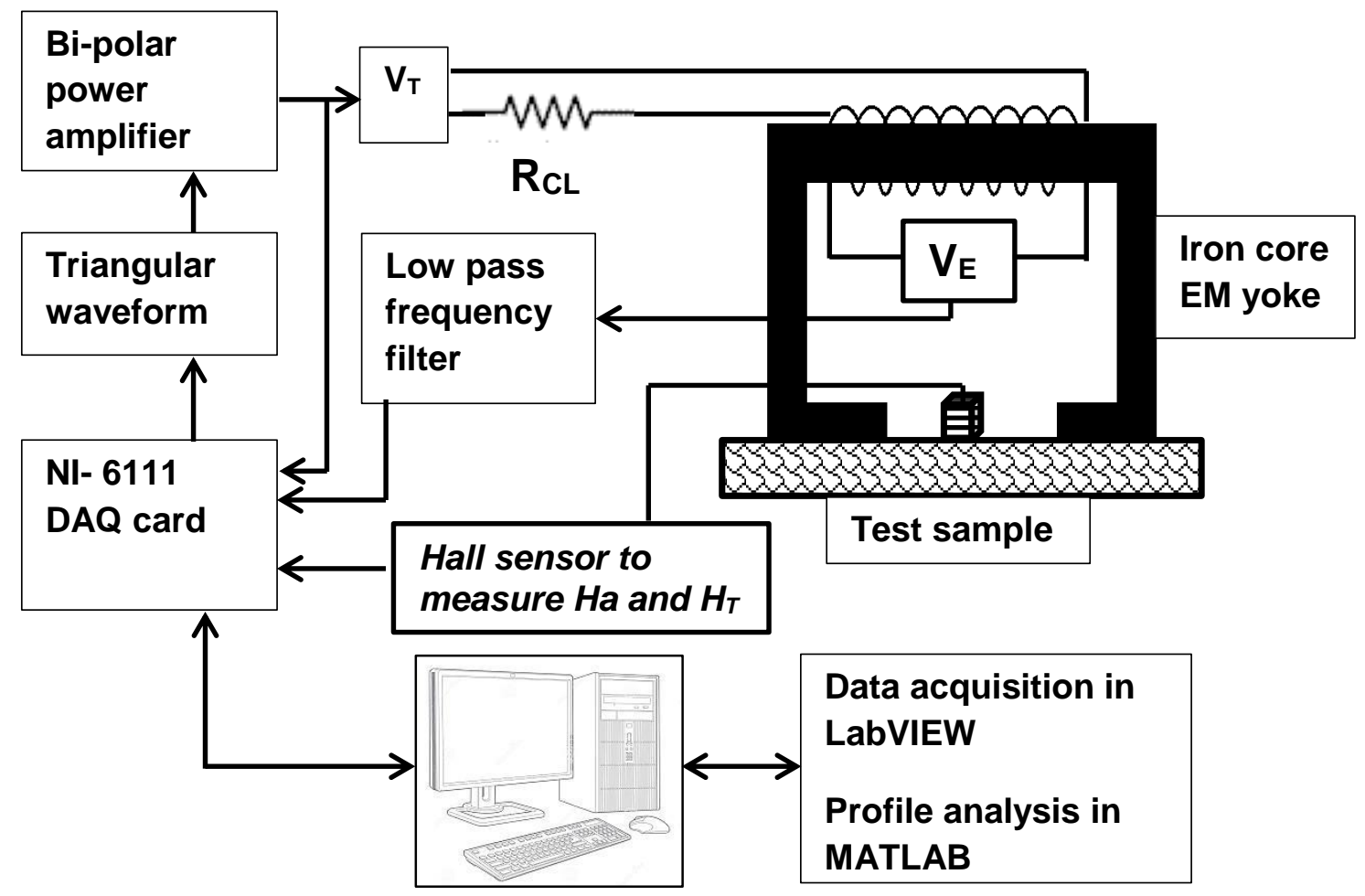

Figure.3. Schematic experimental set-up used for acquiring and analysing distortion of magnetic field strength and magnetic excitation voltage.

\section{Results and Discussion}


This article is author's version published in the Journal of Magnetism and Magnetic Materials, 398 (2016) 101-108.

Final published version of this paper is available at http://dx.doi.org/10.1016/i.jmmm.2015.09.029

The non-linear behaviour of $V_{E}$ has already been reported by the author recently for these samples [9]. In this paper, the non-linear distortion behaviour of tangential magnetic field $\left(\mathrm{H}_{\mathrm{T}}\right)$ and their correlation to the distortion behaviour of magnetic excitation voltage $\left(\mathrm{V}_{\mathrm{E}}\right)$ have been discussed.

\subsection{Distortion Analysis of Tangential Field (DATF)}

The typical variations in the applied magnetic field $\left(\mathrm{H}_{\mathrm{a}}\right)$ measured without any sample between the yoke and that of tangential magnetic field $\left(\mathrm{H}_{\mathrm{T}}\right)$ measured on an isothermally annealed $(\mathrm{IA})$ $18 \mathrm{CrNiMo5}$ steel sample between the poles of the EM yoke are shown in figure 4. The variation in $\mathrm{H}_{T}$ as a function of $\mathrm{V}_{\mathrm{T}}$ is shown for different heat-treated $18 \mathrm{CrNiMo5}$ steel samples in figure 5 for one half of the magnetisation cycle $\left(-\mathrm{V}_{T \max }\right.$ to $\left.+\mathrm{V}_{T \max }\right)$. This distortion of $\mathrm{H}_{T}$ is symmetrical and opposite in the other half cycle from $+\mathrm{V}_{T_{\max }}$ to $-\mathrm{V}_{\mathrm{Tmax}}$. However, there will be small hysteresis in the plot of both $\mathrm{H}_{\mathrm{a}}$ and $\mathrm{H}_{\mathrm{T}}$ in a full cycle due to the magnetic hysteresis effect of the iron core of the EM yoke.

It can be observed from figures 4 and 5 that the variation in applied magnetic field, $\mathrm{H}_{\mathrm{a}}$, is linear without any sample (only air gap) between the poles of the yoke. But the tangential surface magnetic field, $\mathrm{H}_{T}$, varies non-linearly in the presence of a ferritic steel sample between the poles of the yoke, clearly reflecting the distortion of $\mathrm{H}_{\mathrm{T}}$. It is also evident from figure 5 that the non-linear distortion behaviour of $\mathrm{H}_{T}$ is different for steel samples with different microstructures. It can be found from figure 5 that, when following the direction of magnetisation from $-\mathrm{V}_{T \max }$ to $+\mathrm{V}_{T \max }$, the $\mathrm{H}_{T}$ slowly crosses $\mathrm{H}_{\mathrm{a}}$ and deviates away to a maximum difference (after $\mathrm{V}_{T}>0$ ) before coming closer to $\mathrm{H}_{\mathrm{a}}$ again at higher $\mathrm{V}_{\mathrm{T}}$. The maximum difference between $\mathrm{H}_{\mathrm{a}}$ and $\mathrm{H}_{\mathrm{T}}$ occurs between $\sim 5$ to $8 \mathrm{~V}$ of total applied voltage $\left(\mathrm{V}_{\mathrm{T}}\right)$. The region of distinct difference between $\mathrm{H}_{\mathrm{a}}$ and $\mathrm{H}_{\mathrm{T}}$ corresponds to the region of sharp change in the rate of magnetisation (knee region of hysteresis curve). This is a clear indication that the distortion of $\mathrm{H}_{T}$ is definitely influenced by the magnetisation process in the ferromagnetic sample between the poles of the yoke. 


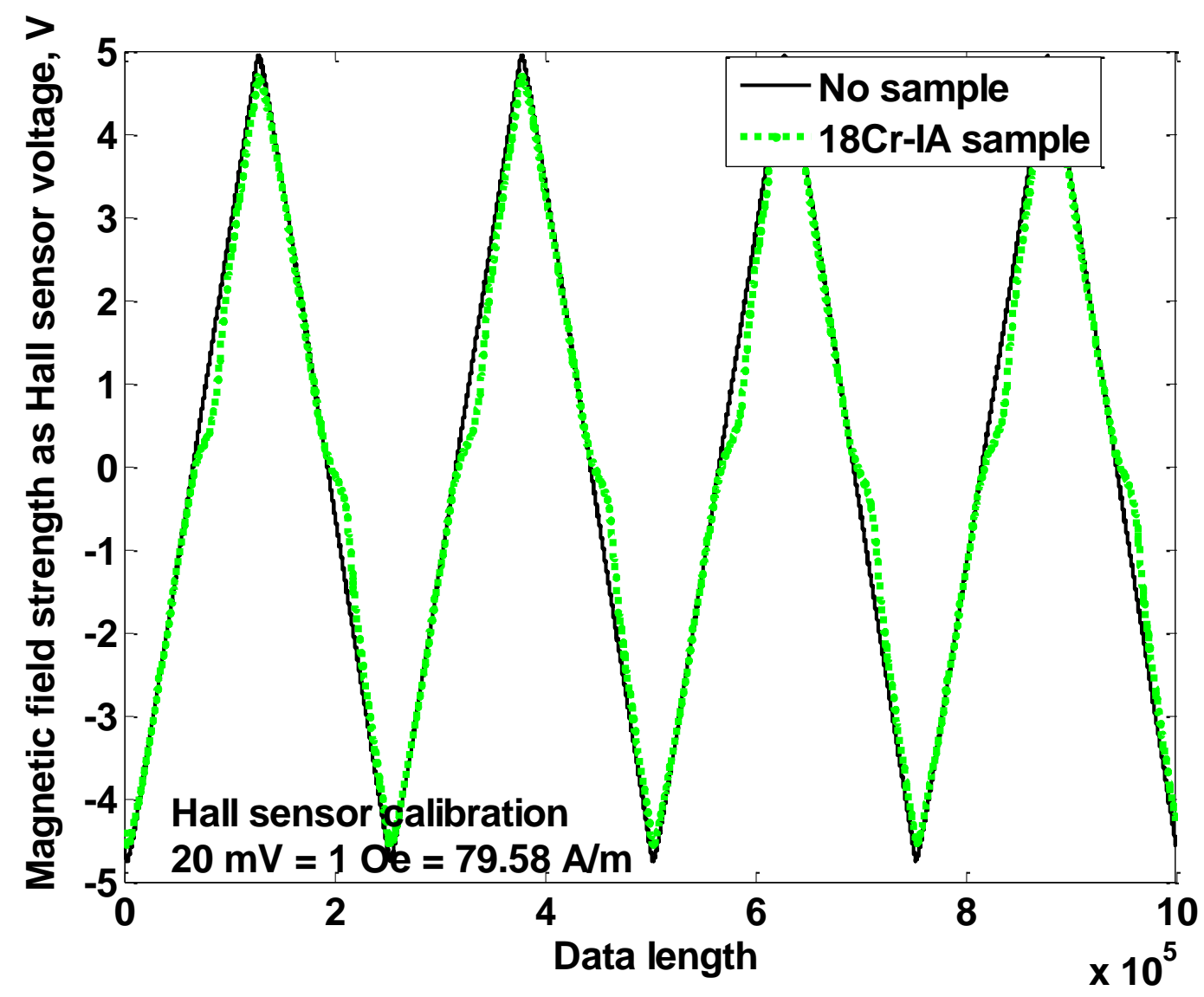

Figure 4. Typical variations in applied magnetic field $\left(\mathrm{H}_{\mathrm{a}}\right)$ measured without any sample and the tangential magnetic field $\left(\mathrm{H}_{\mathrm{T}}\right)$ measured on an isothermally annealed $(\mathrm{IA}) 18 \mathrm{CrNiMo5}$ steel bar sample are shown for a total duration of $10 \mathrm{~s}$ over 4 cycles of magnetisation. The nonlinear distortion in tangential magnetic field $\left(\mathrm{H}_{\mathrm{T}}\right)$ with IA sample can be noticed clearly. The magnetic field strength is shown as Hall sensor voltage which is calibrated to give $20 \mathrm{mV}$ for 1 Oe $(79.58 \mathrm{~A} / \mathrm{m})$. 
This article is author's version published in the Journal of Magnetism and Magnetic Materials, 398 (2016) 101-108.

Final published version of this paper is available at http://dx.doi.org/10.1016/i.jmmm.2015.09.029

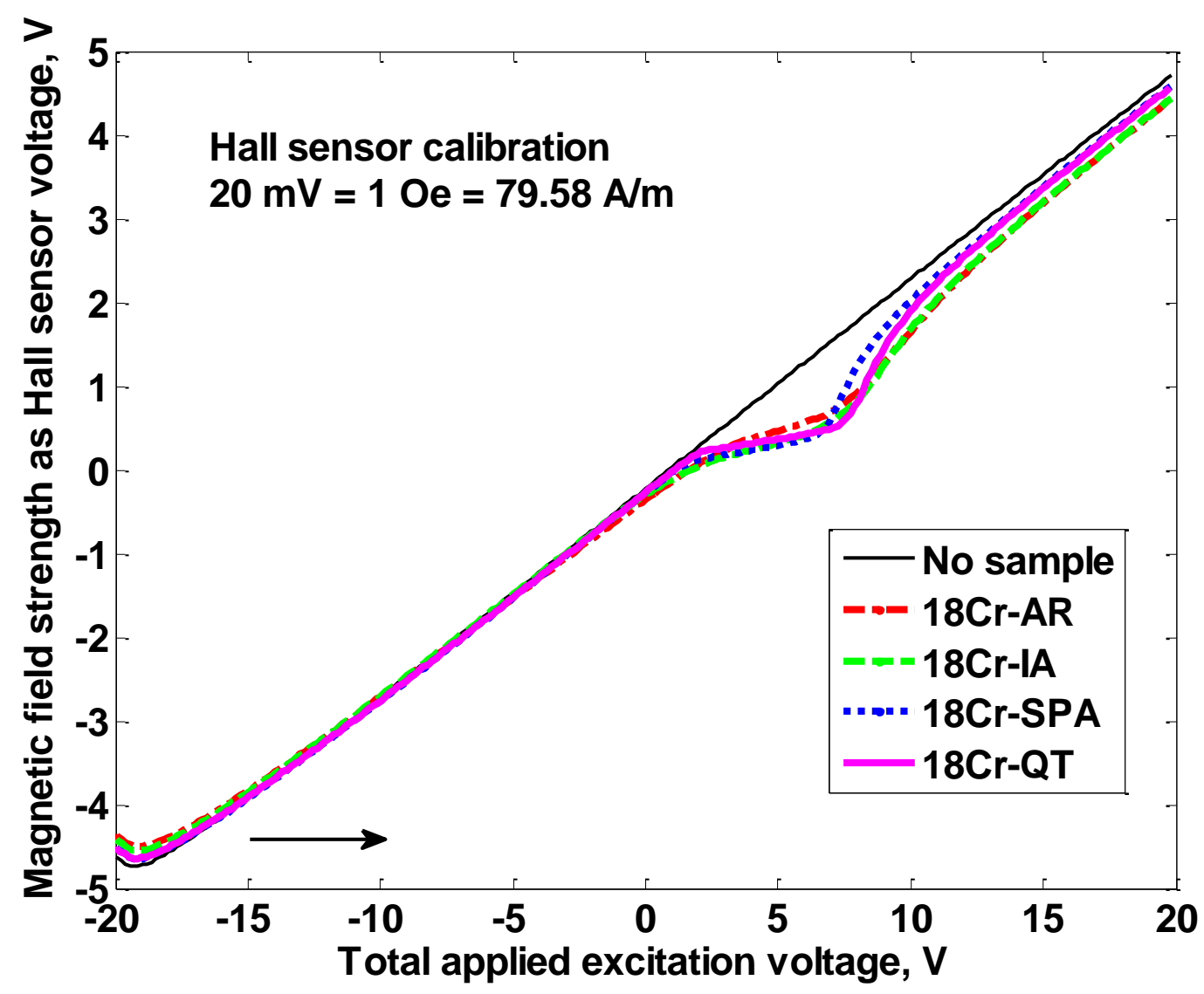

Figure 5. Variations in average applied magnetic field $\left(\mathrm{H}_{\mathrm{a}}\right)$ measured without any sample and average tangential magnetic field $\left(\mathrm{H}_{\mathrm{T}}\right)$ measured with different heat-treated $18 \mathrm{CrNiMo5}$ steel bar samples as a function of total applied voltage $\left(\mathrm{V}_{\mathrm{T}}\right)$ for half the magnetisation cycle $\left(-\mathrm{V}_{\mathrm{Tmax}}\right.$ to $+\mathrm{V}_{\left.T_{\max }\right)}$. The magnetic field strength is shown as Hall sensor voltage which is calibrated to give $20 \mathrm{mV}$ for $1 \mathrm{Oe}(79.58 \mathrm{~A} / \mathrm{m})$.

It has been proposed earlier [7, 8, 20] that, in ferromagnetic steels, during the half cycle of magnetisation process $\left(-\mathrm{H}_{\max }\right.$ to $\left.+\mathrm{H}_{\max }\right)$, the reverse domain walls nucleated at the grain boundaries start moving upon decreasing the applied magnetic field (from $-\mathrm{H}_{\max }$ ) until they are impeded by the second phase carbide, which then overcome the resistance of second phase precipitates and/or the closure domains associated with them at higher applied magnetic field. The initial growth of reverse domain walls from grain boundaries and their pinning by carbide precipitates could result in reduction in local magnetic free pole density and hence the reduction in $\mathrm{H}_{\text {id }}$ during the demagnetisation section from $-\mathrm{H}_{\mathrm{amax}}$ (as shown in figures 1 and 2). This would result in $\mathrm{H}_{T}$ varying closer towards $\mathrm{H}_{a}$ (figure 5) when $\mathrm{V}_{T}$ is $<0$. Corresponding to the knee region of the hysteresis curve, the enlargement of $180^{\circ}$ reverse domains would again contribute to increase in magnetic free poles at the grain boundaries which would again increase the $\mathrm{H}_{\text {id. }}$. The action of $\mathrm{H}_{\text {id }}$ against the direction of applied field would result in $\mathrm{H}_{T}$ less than $\mathrm{H}_{\mathrm{a}}$ (figure 5) when $\mathrm{V}_{\mathrm{T}}$ is $>0$. During the remagnetisation section from coercive force $\left(\mathrm{H}_{\mathrm{c}}\right)$ point to $+\mathrm{H}_{\mathrm{amax}}$, when the domain walls overcome the obstacles and move away, there is again 
This article is author's version published in the Journal of Magnetism and Magnetic Materials, 398 (2016) 101-108.

Final published version of this paper is available at http://dx.doi.org/10.1016/i.jmmm.2015.09.029

increase in local magnetic free pole density around the microstructural features with discontinuity in the magnetisation vector (as shown in figures. 1 and 2), which would again result in further increase in $\mathrm{H}_{\text {id }}$ so that the difference between $\mathrm{H}_{\mathrm{a}}$ and $\mathrm{H}_{T}$ reaches a maximum (at $\left.\mathrm{V}_{\mathrm{T}} \sim 5-9 \mathrm{~V}\right)$. At higher applied magnetic fields $\left(\mathrm{V}_{\mathrm{T}}>9 \mathrm{~V}\right)$, the nucleation of new $180^{\circ}$ reverse domains in the opposite direction of magnetisation and / or $90^{\circ}$ closure domains around the microstructural features would reduce to local magnetic free pole energy and hence the $\mathrm{H}_{\text {id }}$ which again reduces the difference between $\mathrm{H}_{a}$ and $\mathrm{H}_{T}$ (figure 5). During a magnetising cycle, the continuous interaction of domain walls with microstructural features changes the magnitude and direction of the net internal demagnetising field $\left(\mathrm{H}_{\mathrm{id}}\right)$ and hence distort the $\mathrm{H}_{\mathrm{T}}$ non-linearly as observed in figure 5.

Even though, the non-linear distortion of $\mathrm{H}_{\mathrm{T}}$ is unique for each sample having distinct microstructure (figure 5), the distinction between samples with different heat-treated microstructure is more clearly reflected by time derivative of $\mathrm{H}_{\mathrm{a}}$ and $\mathrm{H}_{\mathrm{T}}\left(\left(d H_{a} / d t\right)\right.$ and $\left.\left(d H_{T} / d t\right)\right)$ plotted as a function of total applied voltage $\left(\mathrm{V}_{\mathrm{T}}\right)$ for half the magnetisation cycle ($\mathrm{V}_{T \max }$ to $\left.+\mathrm{V}_{T \max }\right)$ as shown in figure 6 . The plot of $\left(\left(d H_{T} / d t\right)\right.$ vs $\left.\mathrm{V}_{\mathrm{T}}\right)$ is named as the Distortion Analysis of Tangential Field (DATF) profile. The DATF profile in the other half cycle $\left(+\mathrm{V}_{\text {Tmax }}\right.$ to - $\left.V_{T \max }\right)$ is symmetrical, but opposite.

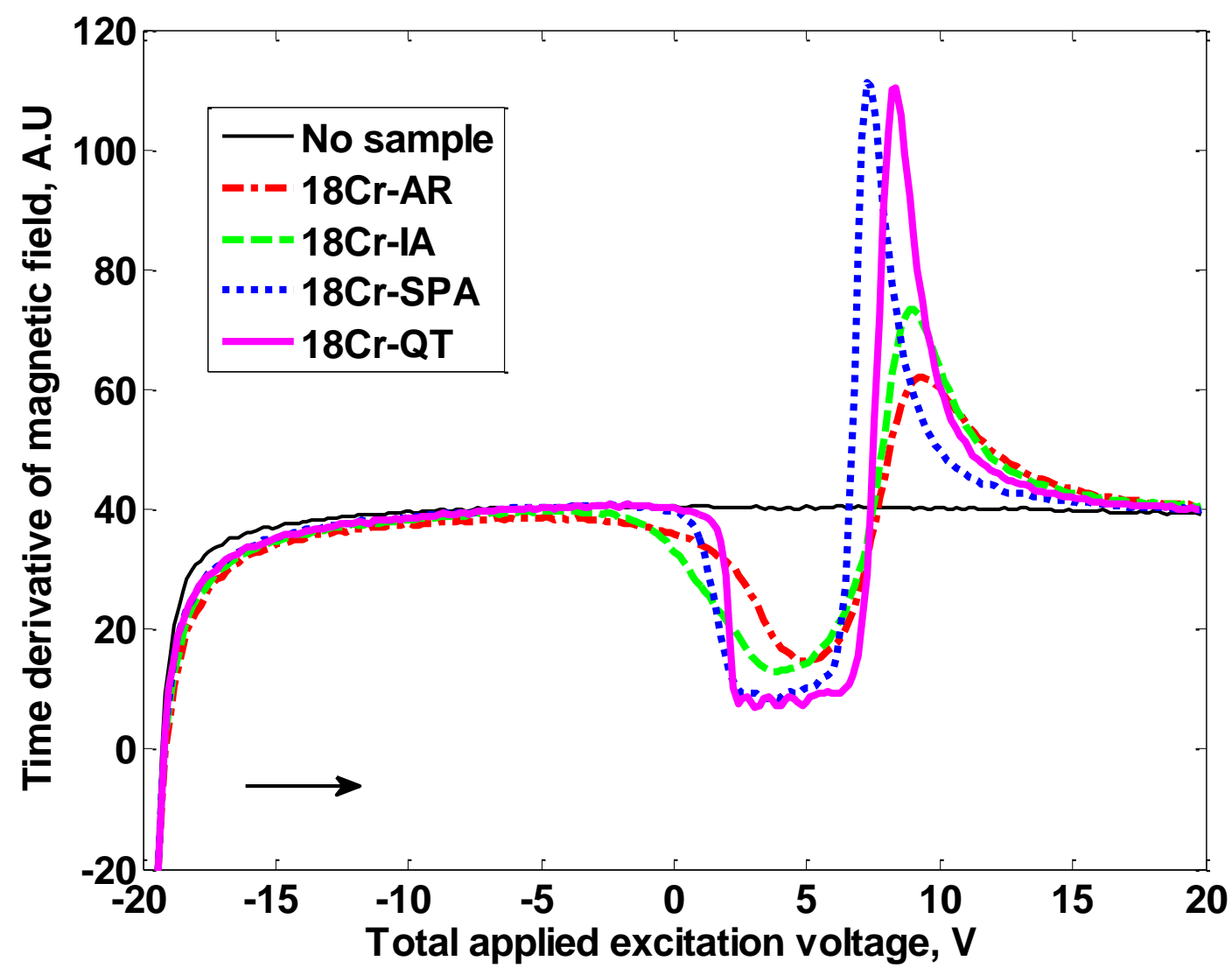

Figure 6. Variations in time derivative of the magnetic field as a function of total applied excitation voltage $\left(\mathrm{V}_{\mathrm{T}}\right)$ measured without any sample $\left(d H_{a} / d t\right)$ and with different heat-treated 
This article is author's version published in the Journal of Magnetism and Magnetic Materials, 398 (2016) 101-108.

Final published version of this paper is available at http://dx.doi.org/10.1016/i.jmmm.2015.09.029

$18 \mathrm{CrNiMo5}$ steel bar samples $\left(d H_{T} / d t\right)$ for half the magnetisation cycle $\left(-\mathrm{V}_{\mathrm{Tmax}}\right.$ to $+\mathrm{V}_{\mathrm{Tmax}}$ as indicated by the arrow).

The DATF profile $\left(\left(d H_{a} / d t\right)\right.$ vs $\left.\mathrm{V}_{\mathrm{T}}\right)$ is almost constant in the absence of any steel sample between the poles of the yoke (figure 6). This supports the constant rate of change of applied magnetic field $\left(d H_{a} / d t\right)$ in correlation to linear change in the excitation voltage, $\mathrm{V}_{\mathrm{T}}$ (constant $\left(d V_{T} / d t\right)$ for triangular waveform excitation). The sharp changes in the $\left(d H_{T} / d t\right)$ values at the ends (near $-\mathrm{V}_{T \max }$ and $+\mathrm{V}_{T_{\max }}$ ) is due to the directional change in the variation of Hall sensor voltage (direction of magnetic field variation). The variation in DATF profile ( $\left(d H_{T} / d t\right)$ vs $\left.\mathrm{V}_{\mathrm{T}}\right)$ in the presence of a different ferromagnetic sample between the poles shows a trough and a peak. The height and position of both the trough and the peak are unique for different heattreated samples. The microstructural details of these samples are given elsewhere [9].

The distinct shape of the DATF profiles $\left(\left(d H_{T} / d t\right)\right.$ vs $\left.\mathrm{V}_{\mathrm{T}}\right)$ (figure 6$)$ for different ferritic steel samples clearly reflects the differences in the mechanism of magnetisation process among these samples with different microstructural features. In the DATF profile, the trough profile, after the minimum, shows a plateau or slight slope before rising towards the sharp peak profile. It can be noticed that the height and position of peak profile shows more distinct shift than that of the trough profile. There is a point of intersection (Pol) of the DATF profile $\left(\left(d H_{T} / d t\right) v s \mathrm{~V}_{\mathrm{T}}\right)$ obtained in the presence of a ferromagnetic steel sample with that of the $\left(\left(d H_{a} / d t\right)\right.$ vs $\left.\mathrm{V}_{\mathrm{T}}\right)$ profile obtained in the absence of any sample (only air gap). This Pol shows small, but finite shift for different samples with respect to $\mathrm{V}_{\mathrm{T}}$ value on $\mathrm{X}$-axis.

The positions of the trough, the peak and the Pol in the DATF profile for as-rolled (AR) sample occur at highest total applied voltages $\left(\mathrm{V}_{\mathrm{T}}\right)$ and gradually shift to lower voltages for IA, QT and SPA samples respectively, indicating the softening of the microstructure. The transition from trough to peak in the DATF profile exhibits different slope changes for different microstructural condition. The interaction of magnetic domain walls with different microstructural features such as dislocations network, lath / grain boundaries, pearlitic lamellae and carbide precipitates etc. will occur at different ranges of magnetic field strengths. This is attributed to differences in the density of magnetic free poles and the local magneto-static energy at the interface between these microstructural features and the surrounding matrix, which in-turn affect the internal demagnetising field $\left(\mathrm{H}_{\mathrm{id}}\right)$ during the displacement of domain walls. Such variations in the micro-mechanism of the magnetisation process will affect the tangential magnetic field (as explained in section 2) resulting in the non-linear distortion of $\mathrm{H}_{T}$ and hence the shape of the DATF profile.

\subsection{Effect of microstructures on the DATF profile}

It would be appropriate, if the changes in the $\left(\boldsymbol{d} \boldsymbol{H}_{\boldsymbol{T}} / \boldsymbol{d t}\right)$ profile are interpreted in terms of the changes in the magnitude and direction of net internal demagnetising field $\left(\mathrm{H}_{\text {id }}\right)$ in the sample and hence the change in $\mathrm{H}_{\mathrm{T}}$. The extent of uniformity of microstructural features and the distribution of domain wall interaction energy will affect the shape of the $\left(\boldsymbol{d} \boldsymbol{H}_{T} / \boldsymbol{d t}\right)$ profile. In the absence of precise understanding on the interaction of magnetic domain walls with different microstructural features during the magnetisation process in polycrystalline materials, 
This article is author's version published in the Journal of Magnetism and Magnetic Materials, 398 (2016) 101-108.

Final published version of this paper is available at http://dx.doi.org/10.1016/i.jmmm.2015.09.029

it would be quite difficult to unambiguously explain the associated changes in the internal demagnetising field $\left(\mathrm{H}_{\mathrm{id}}\right)$ and the distortion of tangential field $\left(\mathrm{H}_{\mathrm{T}}\right)$ at present. However, as one would expect changes in the shape of the magnetic hysteresis curve, the variations in the height and position of the trough and the peak in the DATF $\left(\boldsymbol{d} \boldsymbol{H}_{\boldsymbol{T}} / \boldsymbol{d t}\right)$ profile could be qualitatively explained for different microstructures based on the changes in the magnitude and the direction of the internal demagnetising field $\left(\mathrm{H}_{\text {id }}\right)$ due to domain wall interaction with microstructural features as discussed in the above sections. The position and the height of the trough and the peak derived from the DATF $\left(\boldsymbol{d} \boldsymbol{H}_{T} / \boldsymbol{d} \boldsymbol{t}\right)$ profiles shown in Figure 6 for different samples are given in Table 1.

Table 1: Position and height of the trough and the peak derived from the DATF profiles for different samples. (Note: larger values of height in the trough relates to smaller deviation from no sample condition)

\begin{tabular}{|c|c|c|c|c|}
\hline \multirow{2}{*}{ Sample } & \multicolumn{2}{|c|}{ Trough profile } & \multicolumn{2}{c|}{ Peak profile } \\
\cline { 2 - 5 } & Position, V & Height, A.U & Position, V & Height, A.U \\
\hline 18Cr-AR & 4.68 & 14.73 & 9.19 & 62.04 \\
\hline 18Cr-IA & 3.72 & 12.81 & 8.875 & 73.51 \\
\hline 18Cr-SPA & 2.74 & 9.22 & 7.247 & 111.1 \\
\hline 18Cr-QT & 3.95 & 7.07 & 8.362 & 110.2 \\
\hline
\end{tabular}

In as-rolled (AR) sample, the plastically deformed harder microstructure with high dislocation density would tend to shear the hysteresis curve with low permeability and residual induction and high coercive force. In response to the presence of high density of dislocations network associated with high magnetic free pole density and local magneto-static energy at these crystallographic imperfections, there would always be an increase in the internal demagnetising field $\left(\mathrm{H}_{\text {id }}\right)$ resulting in the decrease in $\mathrm{H}_{\mathrm{T}}$. The presence of high dislocations in the microstructure would severely restrict the movement of domain walls and the magnetisation level. Due to strong $\mathrm{H}_{\text {id }}$, the demagnetisation of the sample (in a hysteresis curve) could start early as seen from the early deviation of DATF $\left(\boldsymbol{d H}_{T} / \boldsymbol{d t}\right)$ profile even before field reversal (when $V_{T}<-2 \mathrm{~V}$ in Figure 6) for AR sample. The effect of dislocations on restricting the magnetisation process can be observed from the smallest heights and the largest positions of both the tough and the peak in AR sample as compared to other samples (Figure 6 and Table 1).

In isothermally annealed (IA) sample, the presence of two-phase microstructure shows the effect of softer ferrite and harder pearlite phases. It has been considered [16] that the polycrystalline grain boundaries are strong sources of magnetic free poles and the internal demagnetising field $\left(\mathrm{H}_{\mathrm{id}}\right)$. In order to reduce the magneto-static energy at the boundaries, the $\mathrm{H}_{\text {id }}$ would aid the nucleation of $180^{\circ}$ reverse domains at the grain boundaries near maximum applied field $\left( \pm \mathrm{V}_{\mathrm{Tmax}}= \pm \mathrm{H}_{\mathrm{amax}}\right)$. Upon reduction in the applied field from the maximum and reversal in the opposite direction, it is possible that the growth of $180^{\circ}$ reverse domains from the grain boundaries would again increase the magnetic free pole density at the boundaries and hence the $H_{i d}$ as explained section 2. This effect can be seen from the larger drop in the trough profile for IA sample at lower field range (in the range of $V_{T}$ from $-1 \mathrm{~V}$ to $3 \mathrm{~V}$ in Figure 6 ) 
This article is author's version published in the Journal of Magnetism and Magnetic Materials, 398 (2016) 101-108.

Final published version of this paper is available at http://dx.doi.org/10.1016/i.jmmm.2015.09.029

as compared to the AR sample. The pearlite phase would also have similar effect apart from its magnetically harder lamellar structure than the ferrite phase, but still softer than the asrolled (AR) structure. This is supported by the positions of the trough and the peak profiles at lower applied voltages (proportional to applied magnetic field) for IA sample as compared to that in the AR sample as can be observed from Figure 6 and Table 1.

In the spheroidising annealed (SPA) sample, the dominant presence of ferrite grain boundaries aid the nucleation of large number of $180^{\circ}$ reverse domains. The growth of large number of reverse domain walls in a narrow field range could result in large increase in net $\mathrm{H}_{\mathrm{id}}$ and hence sharp deviation in $\mathrm{H}_{\mathrm{T}}$. This is reflected as sharp drop in the trough of DATF $\left(\boldsymbol{d} \boldsymbol{H}_{T} / \boldsymbol{d t}\right.$ ) profile in the range of $\mathrm{V}_{\mathrm{T}}$ from $0.5 \mathrm{~V}$ to $1 \mathrm{~V}$ (Figure 6$)$. The presence of large size carbide precipitates could form $90^{\circ}$ spike closure domains to reduce the local magneto-static energy resulting in weak interaction with moving reverse domain walls during remagnetisation (beyond coercive field) which is reflected by the sharp peak at the lowest $V_{T}$ (applied field) for SPA sample. The effect of easier movement of reverse domain walls in the annealed ferrite structure with spheroidised carbides can be seen from the lowest positions of the trough, the peak and the Pol in the DATF $\left(\boldsymbol{d} \boldsymbol{H}_{\boldsymbol{T}} / \boldsymbol{d t}\right)$ profile for SPA sample.

In quenched and tempered (QT) sample, it has been shown that the domain walls could also move easily in low carbon tempered martensitic laths structure resulting in high level of Magnetic Barkhausen Noise (MBN) signals [21]. The martensitic lath boundaries could act similar to the grain boundaries. The narrow size distribution of laths could cause displacement of large number of reverse domains in a narrow field range resulting in sharp change in $\mathrm{H}_{\text {id. }}$. This is reflected by the sharpest drop in trough profile for QT sample (Figure 6). However, the presence of dislocations in the laths and fine carbide precipitates would offer more resistance to domain wall movement as compared to annealed ferrite structure. This effect can be seen from the shift in the positions of the trough and the peak in the DATF $\left(\boldsymbol{d} \boldsymbol{H}_{T} / \boldsymbol{d t}\right)$ profile to higher applied voltages (higher applied field) in QT sample as compared to the SPA sample (Table 1). However, the position of peak is lower in the QT sample as compared to that in the IA and AR samples in which the pearlite phase and dislocations network offer stronger resistance to domain wall movement during remagnetisation.

The effect of magnetically softer to harder microstructural phases such as ferrite, tempered martensite laths, pearlite and as-rolled plastically deformed structure (with high dislocation density) can be observed from the systematic shift in the positions of both trough and the peak to higher applied magnetic field (proportional to total applied voltage) in the DATF $\left(\boldsymbol{d} \boldsymbol{H}_{\boldsymbol{T}} / \boldsymbol{d t}\right.$ ) profile. The height and width of the trough and the peak profile could be considered as an indication of size distribution of these microstructural features and hence the distribution of interaction energy of magnetic domain walls during the magnetisation process. Even though, these statements could be supported by the variations in the $\left(\boldsymbol{d} \boldsymbol{H}_{T} / \boldsymbol{d t}\right)$ profile, more fundamental studies are required to substantiate these arguments.

Since the shape of the DATF ( $\left(d H_{T} / d t\right)$ vs $\left.\mathrm{V}_{\mathrm{T}}\right)$ profile is unique depending on the properties of ferromagnetic material, the DATF profile measurement could be used for evaluation material quality of ferritic steels. Various parameters such as height and position of the trough and peak, area of the trough and peak profile, the point of intersection (Pol) of the DATF profiles without $\left(d H_{a} / d t\right)$ and with a ferromagnetic sample $\left(d H_{T} / d t\right)$ etc. could be correlated 
This article is author's version published in the Journal of Magnetism and Magnetic Materials, 398 (2016) 101-108.

Final published version of this paper is available at http://dx.doi.org/10.1016/i.jmmm.2015.09.029

to variation in material properties such as microstructures and stresses, which influence the movement of magnetic domain walls. Further systematic studies in DATF measurements could help in understanding the mechanism of magnetisation process and correlating to variations in different microstructural features and mechanical properties in different ferritic steels. However, apart from the influence of different material conditions, the non-linear distortion behaviour of tangential field will also be affected by the geometry of the ferritic steel sample due to the effect of external demagnetising field [13] and its contribution to the effective magnetic field strength according the equations (1) and (3) discussed in the section 2. Further understanding of this phenomenon of non-linear distortion of tangential magnetic field is in progress.

\subsection{Comparison of DAME and DATF profiles}

It has been shown earlier $[9,10]$ by the author that, in the presence of a ferromagnetic sample, the variation in $V_{E}$ deviates with an increase corresponding to the demagnetisation of the sample and then decreases again corresponding to the remagnetisation of the sample in a half cycle of magnetisation (from $-\mathrm{V}_{T \max }$ to $+\mathrm{V}_{T \max }$ ), satisfying the Faraday's and Lenz's laws of ferromagnetic induction. Corresponding to this, the distortion analysis of magnetic excitation (DAME) voltage profile $\left(\left(d V_{E} / d t\right)\right.$ vs $\left.\mathrm{V}_{\mathrm{T}}\right)$ shows a peak and trough in a half cycle of magnetisation (from $-V_{T \max }$ to $+V_{T \max }$ ) [9].

The DAME profiles obtained for these 18CrNiMo5 steel samples are shown in figure 7 [9]. For easy comparison, the superimposed DAME and DATF profile are shown in figures 8 and 9. It can be found from Fig.7 that the DAME profile shows first a peak and then a trough during the half cycle of magnetisation $\left(-\mathrm{V}_{T_{\max }}\right.$ to $\left.+\mathrm{V}_{T_{\max }}\right)$ just opposite to the DATF profiles (figure 6$)$. Interestingly, it can be found from figures 8 and 9 that the peak position of the DAME profiles coincides with the trough position of the DATF profile. Similarly, the trough position of the DAME profile coincides with the peak position of the DATF profiles. The unique shape of the DAME and DATF profiles clearly shows the effect of different magnetisation behaviour of the ferritic steel samples with different material properties. It can be observed by comparing Figures 6 to 9 that there is clear correlation between the variation in the shape of peak profile in the DAME and the trough profile in the DATF profile over the entire range of total applied voltage (applied magnetic field). The variations in the slopes of the ascending peak of the DAME profiles is very similar, but in the opposite direction, to that of the descending slopes of the trough in the DATF profiles. For example, in the IA sample, the early increase in the ascending peak of DAME profile is reflected by the early drop in the trough of the DATF profile (near $\mathrm{V}_{\mathrm{T}}<0$ ). Similarly, in the QT sample, the sharp increase in the ascending peak of the DAME profile is correlates with sharp drop in the descending trough of the DATF profile. 
This article is author's version published in the Journal of Magnetism and Magnetic Materials, 398 (2016) 101-108.

Final published version of this paper is available at http://dx.doi.org/10.1016/i.jmmm.2015.09.029

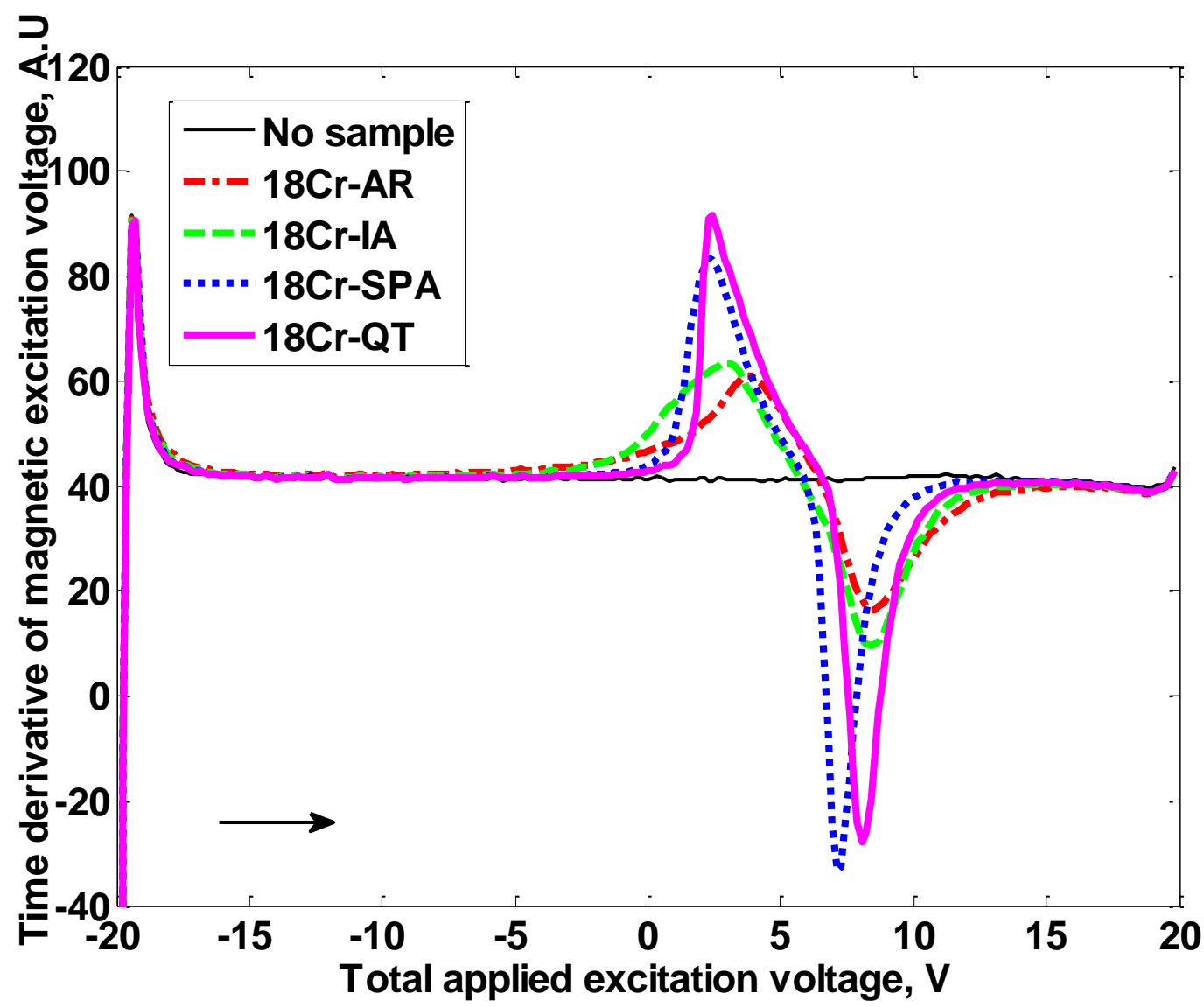

Figure 7. Variations in time derivative of the magnetic excitation voltage across the EM yoke $\left(d V_{E} / d t\right)$ as a function of total applied excitation voltage $\left(\mathrm{V}_{\mathrm{T}}\right)$ measured without any sample and with different heat-treated $18 \mathrm{CrNiMo5}$ steel bar samples for half the magnetisation cycle $\left(-\mathrm{V}_{\mathrm{Tmax}}\right.$ to $\left.+\mathrm{V}_{\mathrm{Tmax}}\right)[9]$. 
This article is author's version published in the Journal of Magnetism and Magnetic Materials, 398 (2016) 101-108.

Final published version of this paper is available at http://dx.doi.org/10.1016/i.jmmm.2015.09.029

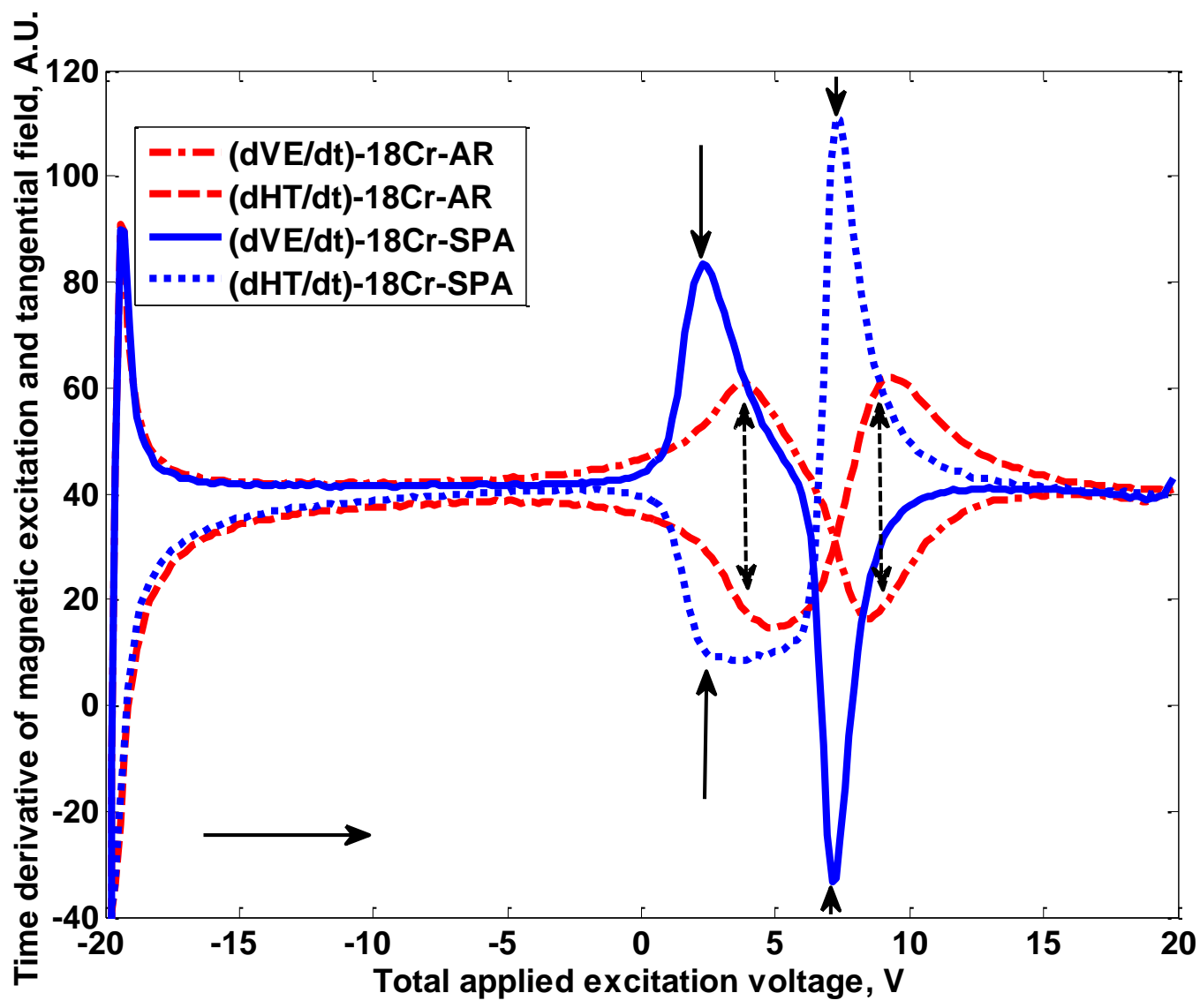

Figure 8. Superimposed DAME $\left(d V_{E} / d t\right)$ and DATF $\left(d H_{T} / d t\right)$ profiles as a function of total applied excitation voltage $\left(\mathrm{V}_{\mathrm{T}}\right)$ measured with $18 \mathrm{CrNiMo5}$ steel $\mathrm{AR}$ and SPA samples for half the magnetisation cycle $\left(-\mathrm{V}_{T_{\max }}\right.$ to $\left.+\mathrm{V}_{T_{\max }}\right)$. (TF denotes the tangential field, $\left(d H_{T} / d t\right)$ and $\mathrm{ME}$ denotes the magnetic excitation voltage, $\left.\left(d V_{E} / d t\right)\right)$. 
This article is author's version published in the Journal of Magnetism and Magnetic Materials, 398 (2016) 101-108.

Final published version of this paper is available at http://dx.doi.org/10.1016/i.jmmm.2015.09.029

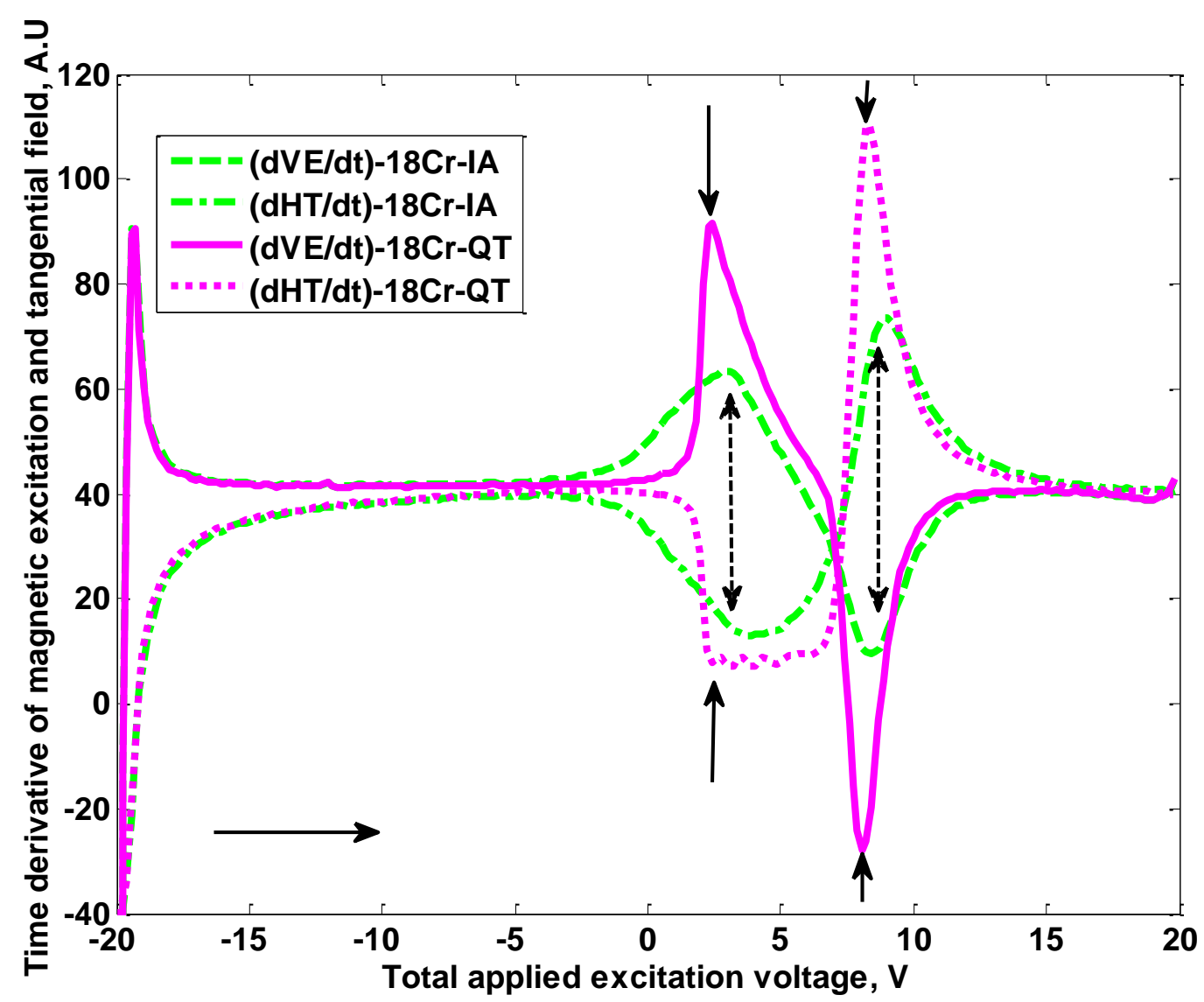

Figure 9. Superimposed DAME $\left(d V_{E} / d t\right)$ and DATF $\left(d H_{T} / d t\right)$ profiles as a function of total applied excitation voltage $\left(\mathrm{V}_{\mathrm{T}}\right)$ measured with $18 \mathrm{CrNiMo5}$ steel IA and QT samples for half the magnetisation cycle $\left(-\mathrm{V}_{T \max }\right.$ to $\left.+\mathrm{V}_{T \max }\right)$. (TF denotes the tangential field, $\left(d H_{T} / d t\right)$ and $\mathrm{ME}$ denotes the magnetic excitation voltage, $\left.\left(d V_{E} / d t\right)\right)$.

The distinctive correlation between DAME and DATF profiles clearly indicates that both the DAME and DATF profiles are influenced by the same magnetisation process in the ferromagnetic material introduced between the poles of the EM yoke. The material properties such as composition, microstructure and stresses in the ferromagnetic material will strongly influence the magnetisation process and hence the shape of the DAME and DATF profile. There is distinct difference between the shape of DAME and DATF profiles. The DAME profile shows more or less narrow peak and trough profiles whereas the DATF profile shows broader trough profile and a narrow peak profile (Figures 8 and 9). It is expected that the DAME profile is influenced by the rate of change of permeability (or magnetic flux) whilst the DATF profile is influenced by the continuous changes in the net internal demagnetising field $\left(H_{\text {id }}\right)$ in the sample. This could indicate the differences in the way the magnetisation process affect the DAME and DATF profiles which needs further understanding.

The continuous variation in the magnitude and direction of internal demagnetising field, $\mathrm{H}_{\mathrm{id}}$, results in the non-linear distortion of $\mathrm{H}_{T}$ and the specific shape of the DATF profile. Similarly, the different interactions of magnetic domain walls with different microstructural features result in variation in the rate of change of magnetisation in the ferromagnetic material which causes 
This article is author's version published in the Journal of Magnetism and Magnetic Materials, 398 (2016) 101-108.

Final published version of this paper is available at http://dx.doi.org/10.1016/i.jmmm.2015.09.029

non-linear distortion of $V_{E}$ and the DAME profile. The unique shape of the DAME and DATF profiles reveals some distinct variations in the magnetisation process which require further systematic studies to understand in more detail. It appears that the analysis of DAME and DATF profiles could give much more information about the influence of different properties such as microstructure and stresses on the magnetisation process than the traditional magnetic hysteresis (B-H) curve. In addition, the measurements of DAME and DAFT profiles are much simpler and easier to apply on ferromagnetic structures / components with complex geometry. However, it is important to understand that the external demagnetisation effect due to geometry of the ferromagnetic sample / component will affect the effective magnetic field and the magnetisation range and hence the shape of the DAME and DATF profiles. The analysis of different parameters such as height, position, area of peak and trough, the Pol of both DAME and DATF profile (as defined elsewhere in [10]) would give better understanding on the influence of different material properties on the magnetisation process. It is also expected that there will be definite correlation between the DAME - $\left(d V_{E} / d t\right)$, the DATF $\left(d H_{T} / d t\right)$ and the derivative of magnetic flux $(\varnothing)$ profiles which will be studied in the future.

\section{Conclusions}

This study clearly shows that the tangential magnetic field $\left(\mathrm{H}_{\mathrm{T}}\right)$ is non-linearly distorted in a way similar, but opposite to that of magnetic excitation voltage $\left(V_{E}\right)$ across the coil around the EM yoke in the presence of a ferromagnetic sample placed between the poles. Subtle changes in material properties is distinctly reflected by the variations in the shape of the time derivative profiles of the $\mathrm{V}_{\mathrm{E}}$ and $\mathrm{H}_{\mathrm{T}}$ (DAME - $\left(d V_{E} / d t\right)$ and DATF - $\left(d H_{T} / d t\right)$ profiles).

Clear dependency of the non-linear distortion behaviour of $\mathrm{V}_{E}$ and $\mathrm{H}_{T}$ on the microstructural condition of the sample supports the influence of variation in the mechanism of magnetisation process in ferromagnetic materials with different microstructures and stresses.

Even though, the DAME and DATF profile measurements are based on two different concepts, the systematic shift in the height and position of the peak and the trough in both the DAME $\left(d V_{E} / d t\right)$ and DATF $\left(d H_{T} / d t\right)$ profiles could potentially be used to identify different microstructural and stress states of ferromagnetic materials as well as understand the mechanism of magnetisation process in different ferromagnetic materials.

The simple measurement approach of distortion analysis of magnetic excitation voltage and tangential field could be successfully used for several of applications related to evaluation of variations in chemical composition, microstructure and mechanical properties in ferromagnetic steel components. These magnetic methods have the potential for non-destructive evaluation of quality of heat-treatment process, fatigue damage, high-temperature thermal damage, manufacturing process etc. in ferromagnetic materials. Further systematic study is required for better understanding of the physical significance of these unexplored ferromagnetic phenomena and modelling the non-linear distortion of $\mathrm{V}_{E}$ and $\mathrm{H}_{T}$ and their relation to microstructural and mechanical properties of ferromagnetic materials. 
This article is author's version published in the Journal of Magnetism and Magnetic Materials, 398 (2016) 101-108.

Final published version of this paper is available at http://dx.doi.org/10.1016/i.jmmm.2015.09.029

\section{Acknowledgement}

The author acknowledges the support of Design Unit, School of Mechanical and Systems Engineering, Newcastle University, UK during this study.

\section{References:}

1. W.A. Theiner and I. Altpeter, Determination of residual stress using micro-magnetic parameters, in P.Holler (Ed.), New procedures in Non-destructive Testing, Springer, Heidelberg, 1983, 575-580.

2. D.C. Jiles 1988 Review of magnetic methods for non-destructive evaluation, NDT International, 21(5) (1988) 311-319.

3. M.K. Devine 1992 The magnetic detection of material properties, $\mathrm{J}$ of the Minerals, Metals and Materials Society, 44 (10) (1992) 24-30.

4. O. Stupakov, J. Pal'a, V. Yurchenko, I. Tomas and J. Bydzovsky, Measurement of Barkhausen noise and its correlation with magnetic permeability, J. Magn. Magn. Mater., 320 (3-4) (2008) 204-209.

5. C. Zhang, N. Bowler and C. Lo, Magnetic characterisation of surface hardened steels, J. Magn. Magn. Mater., 321 (2009) 3878 - 3887.

6. J.W. Wilson, N. Karimian, J. Liu, W. Yin, C.L. Davis and A.J. Peyton, Measurement of the magnetic properties of P9 and T22 steel taken from service in power station, J. Magn. Magn. Mater., 360 (2014) 52-58.

7. V. Moorthy, S.Vaidyanathan, T. Jayakumar and Baldev Raj, "Microstructural Characterization in quenched and tempered $0.2 \%$ carbon steel using Magnetic Barkhausen Noise", J. Magn. Magn. Mater, 171 (1997) 179-189.

8. V. Moorthy, S.Vaidyanathan, T. Jayakumar and Baldev Raj, On the influence of tempered Microstructures on magnetic Barkhausen emission in ferritic steels, Phil. Mag. A, 77 (6) (1998) 1499-1514.

9. V. Moorthy, Distortion Analysis of Magnetic Excitation - A novel approach for nondestructive microstructural evaluation of ferromagnetic steel, J.Phys. D:- Appl. Phys, 47, (2014) 202001, doi:10.1088/0022-3727/47/20/202001.

10. V. Moorthy, Distortion Analysis of Magnetic Excitation - Inherent reflection of properties of ferromagnetic materials, J. Magn. Magn. Mater., 382 (2015) 58-62.

11. G. Dobmann and H. Pitsch, Magnetic tangential field strength inspection a further NDTtool for 3MA Non-Destructive Characterization of Materials 3, ed P Holler, V Hauk, G Dobmann, C Ruud and R Green, (Berlin: Springer), 1989, 636.

12. Iris Altpeter, Rainer Becker, Gerd Dobmann, RolfKern, Werner Theiner and Andreij Yashan, Robust solutions of inverse problems in electromagnetic non-destructive evaluation, Inverse Problems, 18 (2002) 1907-1921. 
This article is author's version published in the Journal of Magnetism and Magnetic Materials, 398 (2016) 101-108.

Final published version of this paper is available at http://dx.doi.org/10.1016/i.jmmm.2015.09.029

13. Oleksandr Stupakov, Investigation of applicability of extrapolation method for sample field determination in single-yoke measuring setup, Journal of Magnetism and Magnetic Materials 307 (2006) 279-287.

14. D.K. Bhattacharya and S.Vaidyanathan, Effect of demagnetisation factor on the Barkhausen noise signal, J. Magn. Magn. Mater., 166 (1997) 111-116.

15. A.P. Gusev and S.A. Kosovets, Effect of demagnetising action of an interface on the field of surface flaws upon magnetisation with an attached electromagnet, Russian Journal of Non-destructive Testing, 42 (5) (2006) 315-320.

16. J.B. Goodenough, A theory of domain creation and coercive force in polycrystalline ferromagnetics, Phy. Rev., 95 (4) (1954) 917-932.

17. L.F. Bates and D.H. Martin, Ferromagnetic Domain nucleation in Silicon Iron, Proc. Phys. Soc. 69 (2-B) (1965) 145-152.

18. R.S. Tebble and D.J. Craik, Magnetic Materials, Wiley Interscience, New York, 1969, 369-411.

19. T. R. Haller and J. J. Kramer, Model for Reverse-Domain Nucleation in Ferromagnetic Conductors, J. App. Phys, 41(3) (1970) 1036-1037.

20. L. Batisa, U. Rabe, I. Altpeter, S. Hirsekorn and G. Dobmann, On the Mechanism of non-destructive evaluation of cementite content in steels using a combination of magnetic Barkhausen noise and magnetic force microscopy techniques, J. Magn. Magn. Mater., 354 (2014) 248-256.

21. M. Vashista and V. Moorthy, On the shape of the magnetic Barkhausen noise profile for better revelation of the effect of microstructures on the magnetisation process in ferritic steels, J. Magnetism and Magnetic Materials, 393, 2015, 584-592. http://dx.doi.org/10.1016/j.jmmm.2015.06.008. 
This article is author's version published in the Journal of Magnetism and Magnetic Materials, 398 (2016) 101-108.

Final published version of this paper is available at http://dx.doi.org/10.1016/i.jmmm.2015.09.029

Figures in colour for on-line publication

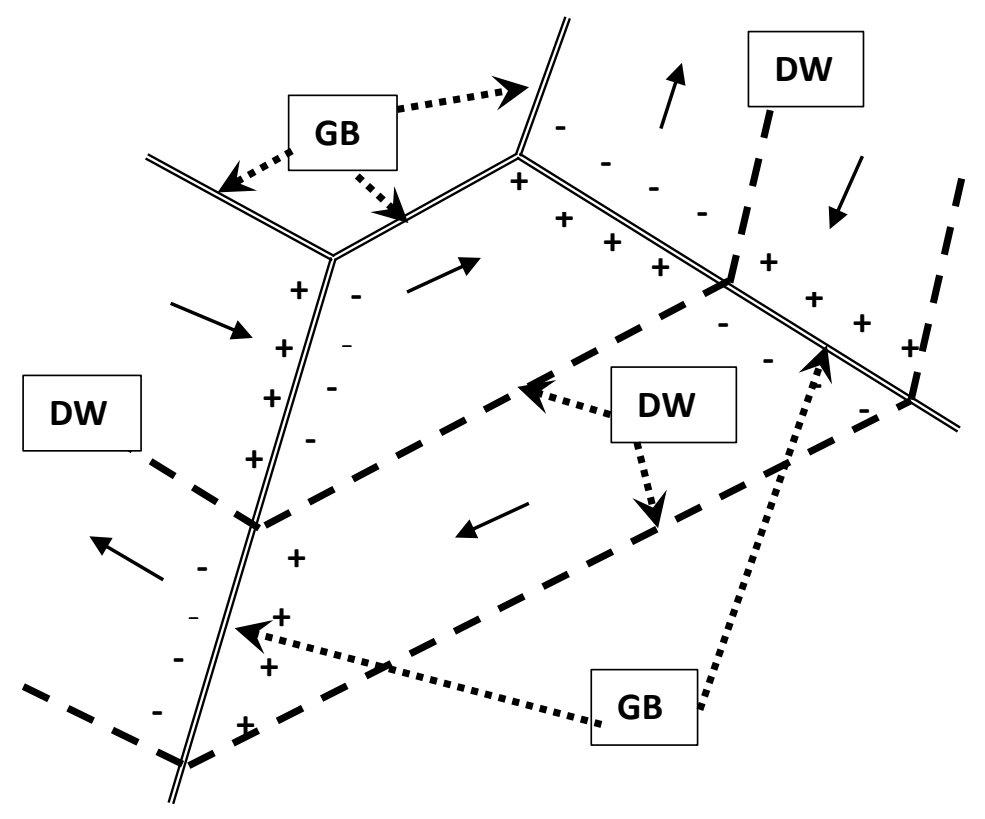

(a)

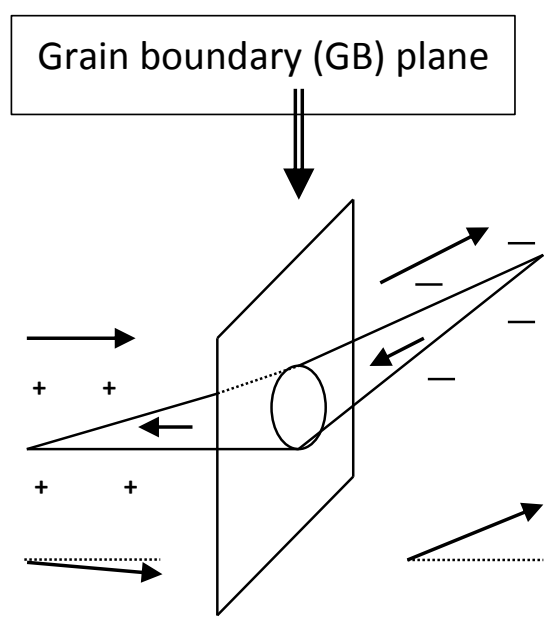

(b)

Figure 1. (a) Multi-domain structure in a thermally demagnetized polycrystalline material with magnetic free poles at the grain boundary (GB) interface and (b) Schematic of formation of reverse spike domain structure at a grain boundary (GB) to reduce the boundary surface magnetic free pole density. (DW refers to Domain Wall). 
This article is author's version published in the Journal of Magnetism and Magnetic Materials, 398 (2016) 101-108.

Final published version of this paper is available at http://dx.doi.org/10.1016/i.jmmm.2015.09.029
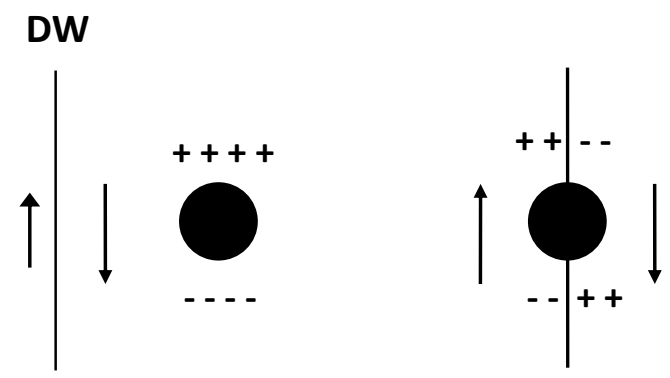

$H_{\text {id }}$

$\mathrm{H}_{\mathrm{id}} / \mathbf{2}$

(a)

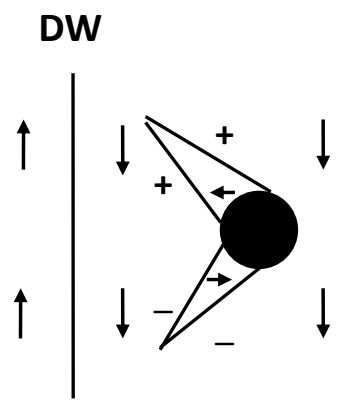

$H_{\text {id }}$

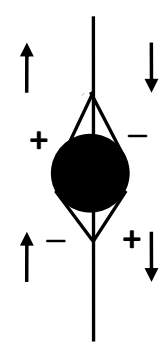

$\mathrm{H}_{\mathrm{id}} / \mathbf{2}$

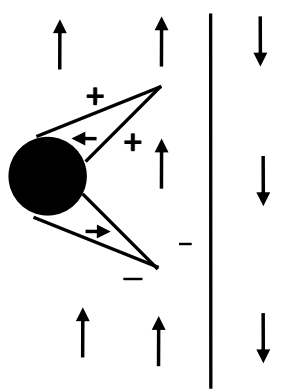

$H_{\text {id }}$ 
This article is author's version published in the Journal of Magnetism and Magnetic Materials, 398 (2016) 101-108.

Final published version of this paper is available at http://dx.doi.org/10.1016/i.jmmm.2015.09.029

(b)

Figure 2. Schematic of interaction of $180^{\circ}$ domain wall with inclusion / precipitate, (a) without closure domain and (b) with closure domain resulting in redistribution of magnetic free poles at the interface and hence reduction in internal demagnetizing field $\left(\mathrm{H}_{\mathrm{id}}\right)$.

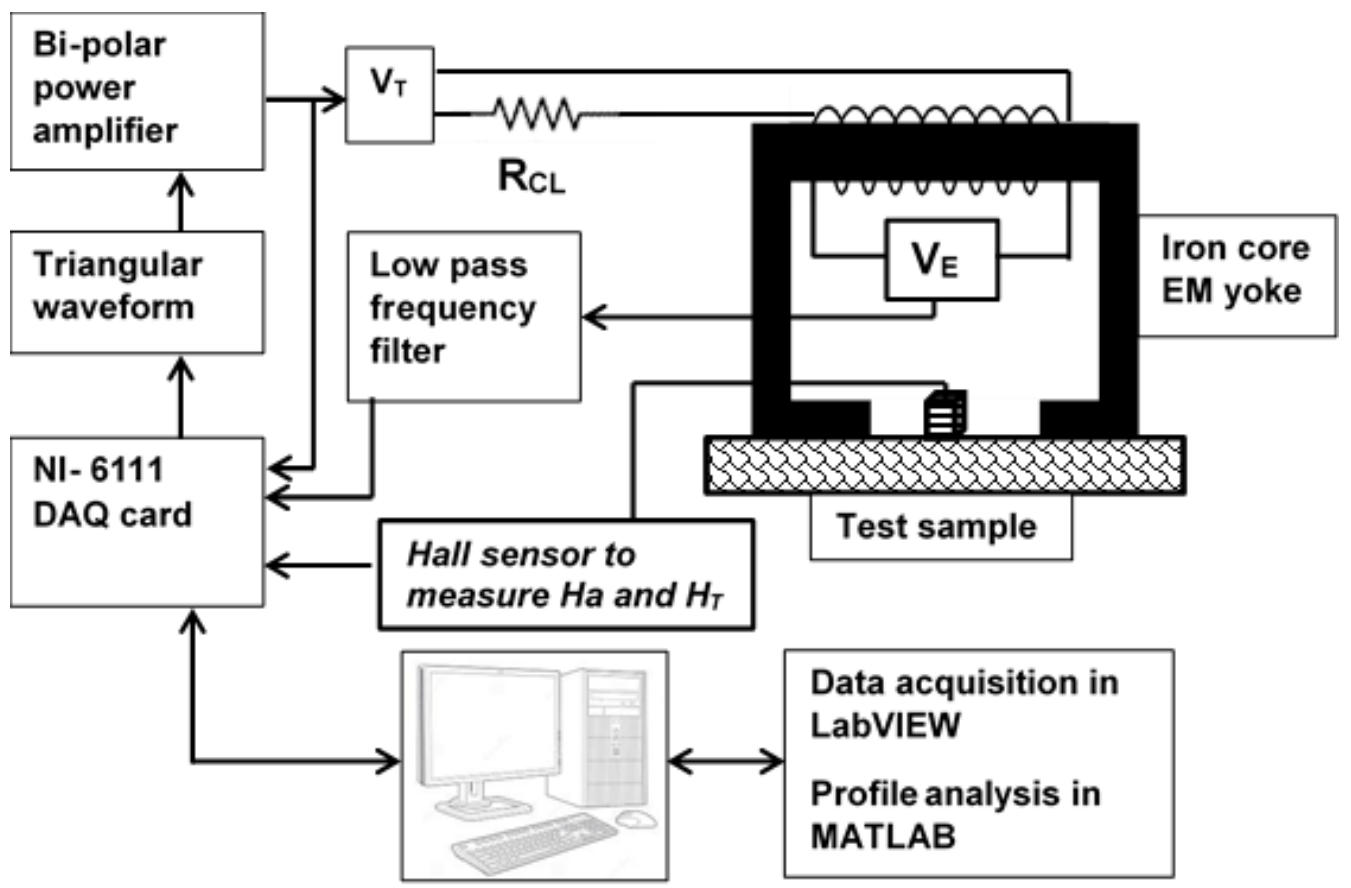

Figure 3. Schematic experimental set-up used for acquiring and analysing distortion of magnetic field strength and magnetic excitation voltage. 
This article is author's version published in the Journal of Magnetism and Magnetic Materials, 398 (2016) 101-108.

Final published version of this paper is available at http://dx.doi.org/10.1016/i.jmmm.2015.09.029

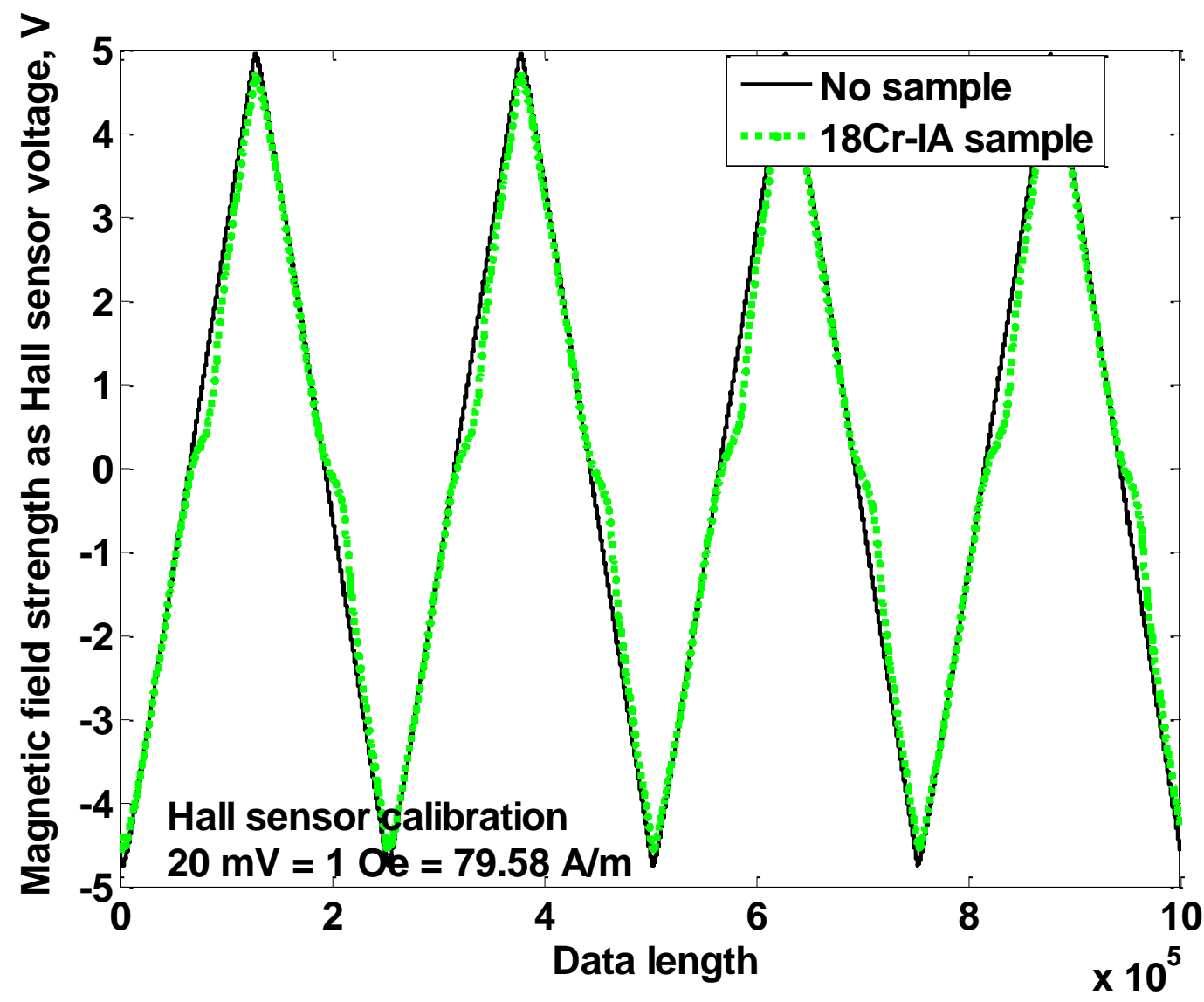

Figure 4. Typical variations in applied magnetic field $\left(\mathrm{H}_{\mathrm{a}}\right)$ measured without any sample and the tangential magnetic field $\left(\mathrm{H}_{\mathrm{T}}\right)$ measured on an isothermally annealed $(\mathrm{IA}) 18 \mathrm{CrNiMo5}$ steel bar sample are shown for a total duration of $10 \mathrm{~s}$ over 4 cycles of magnetisation. The nonlinear distortion in tangential magnetic field $\left(\mathrm{H}_{\mathrm{T}}\right)$ with IA sample can be noticed clearly. The magnetic field strength is shown as Hall sensor voltage which is calibrated to give $20 \mathrm{mV}$ for 1 Oe $(79.58 \mathrm{~A} / \mathrm{m})$. 
This article is author's version published in the Journal of Magnetism and Magnetic Materials, 398 (2016) 101-108.

Final published version of this paper is available at http://dx.doi.org/10.1016/i.jmmm.2015.09.029

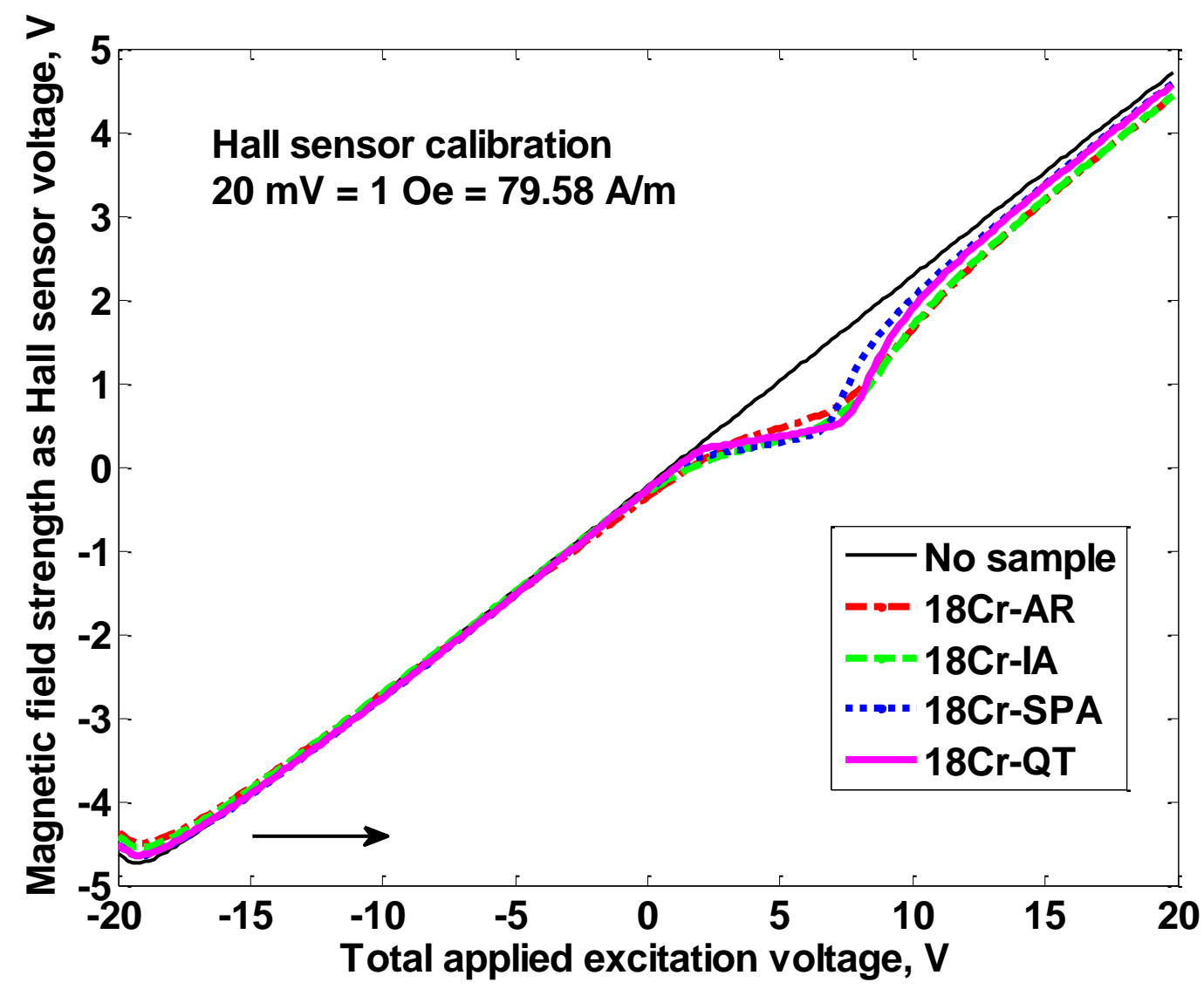

Figure 5. Variations in average applied magnetic field $\left(\mathrm{H}_{\mathrm{a}}\right)$ measured without any sample and average tangential magnetic field $\left(\mathrm{H}_{\mathrm{T}}\right)$ measured with different heat-treated $18 \mathrm{CrNiMo5}$ steel bar samples as a function of total applied voltage $\left(\mathrm{V}_{\mathrm{T}}\right)$ for half the magnetisation cycle $\left(-\mathrm{V}_{\mathrm{Tmax}}\right.$ to $+\mathrm{V}_{\left.T_{\max }\right)}$. The magnetic field strength is shown as Hall sensor voltage which is calibrated to give $20 \mathrm{mV}$ for 1 Oe $(79.58 \mathrm{~A} / \mathrm{m})$. 
This article is author's version published in the Journal of Magnetism and Magnetic Materials, 398 (2016) 101-108.

Final published version of this paper is available at http://dx.doi.org/10.1016/i.jmmm.2015.09.029

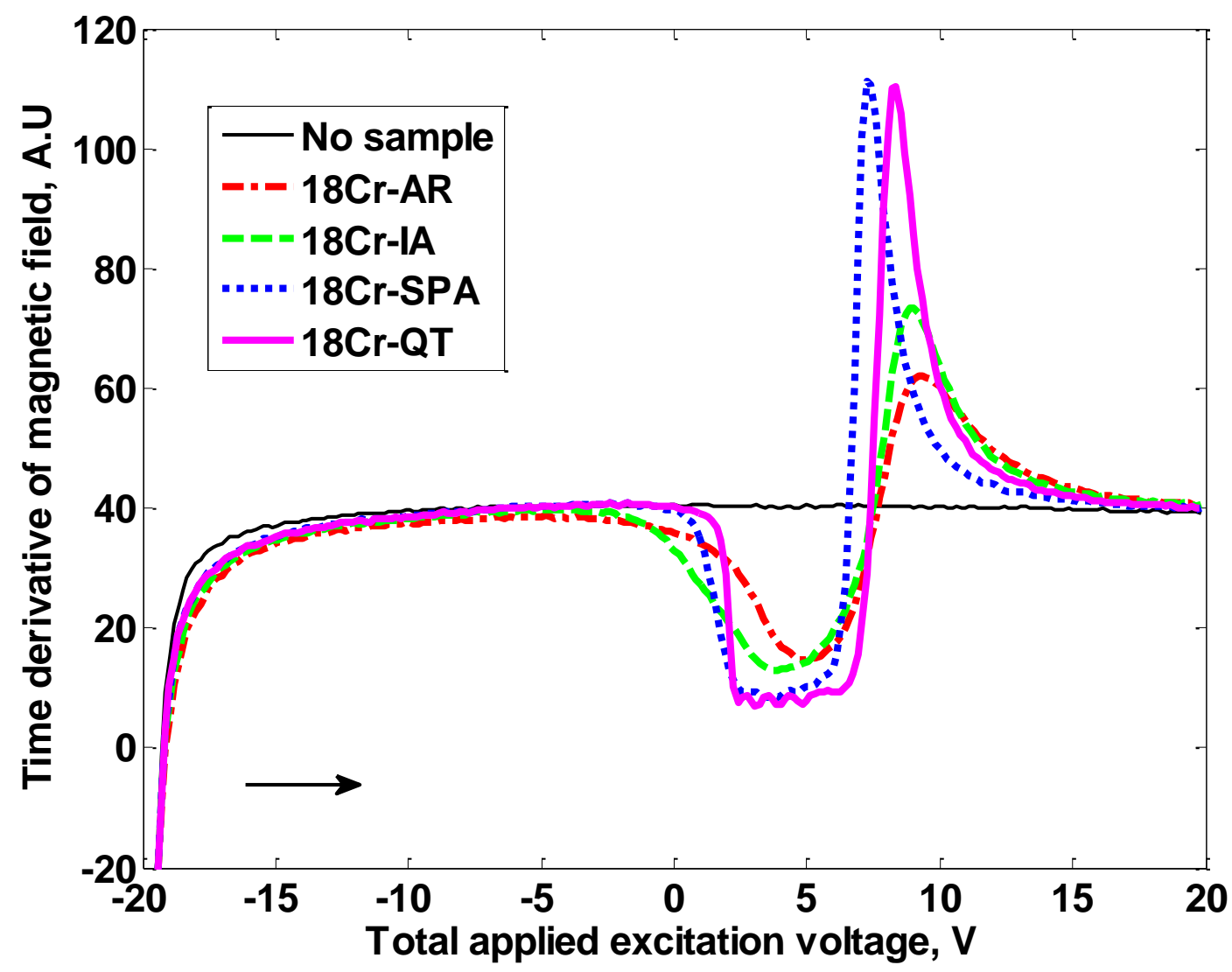

Figure 6. Variations in time derivative of the magnetic field as a function of total applied excitation voltage $\left(\mathrm{V}_{\mathrm{T}}\right)$ measured without any sample $\left(d H_{a} / d t\right)$ and with different heat-treated $18 \mathrm{CrNiMo5}$ steel bar samples $\left(d H_{T} / d t\right)$ for half the magnetisation cycle $\left(-\mathrm{V}_{\mathrm{Tmax}}\right.$ to $\left.+\mathrm{V}_{\mathrm{Tmax}}\right)$. 
This article is author's version published in the Journal of Magnetism and Magnetic Materials, 398 (2016) 101-108.

Final published version of this paper is available at http://dx.doi.org/10.1016/i.jmmm.2015.09.029

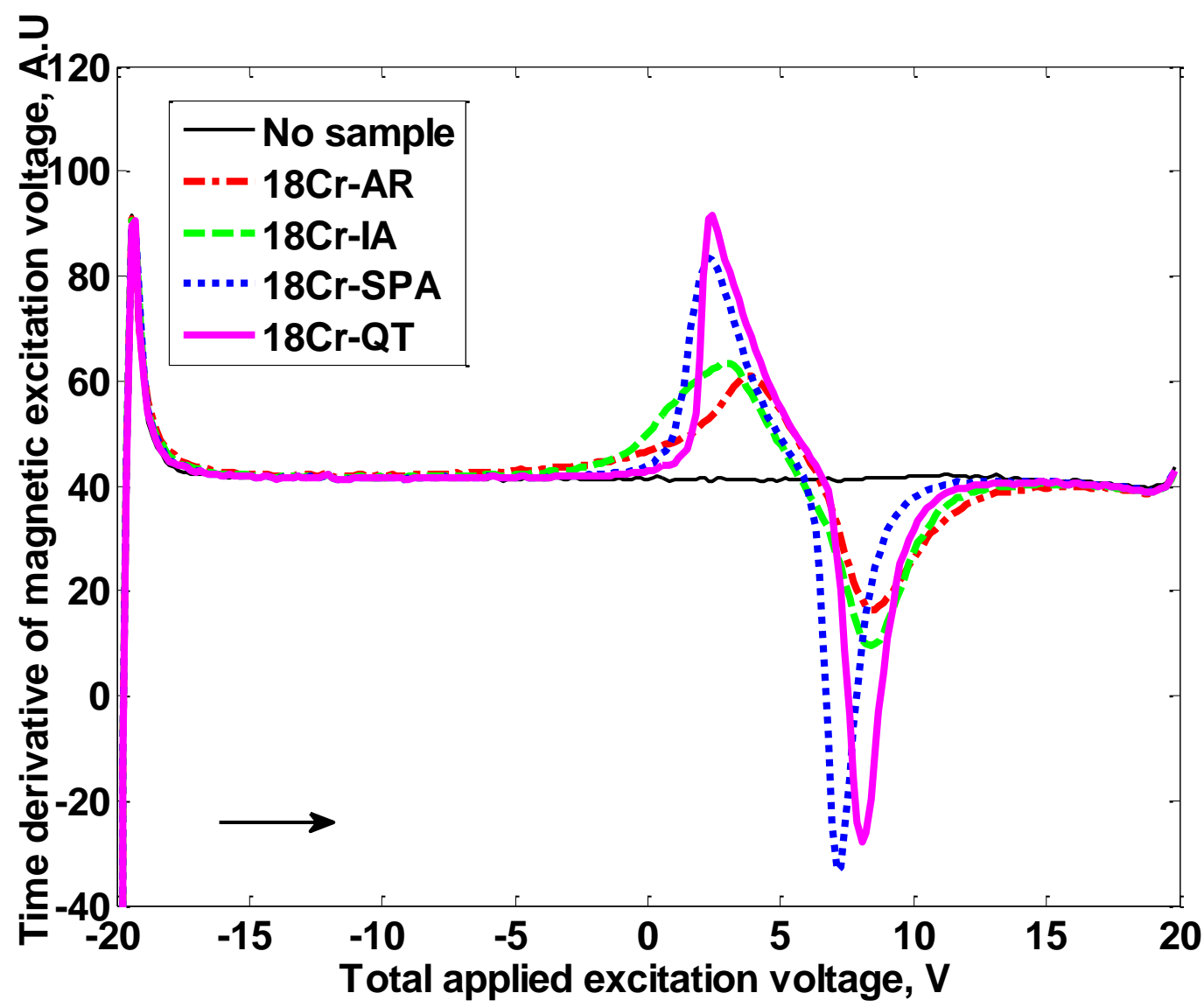

Figure 7. Variations in time derivative of the magnetic excitation voltage across the EM yoke $\left(d V_{E} / d t\right)$ as a function of total applied excitation voltage $\left(\mathrm{V}_{\mathrm{T}}\right)$ measured without any sample and with different heat-treated $18 \mathrm{CrNiMo5}$ steel bar samples for half the magnetisation cycle $\left(-\mathrm{V}_{\mathrm{Tmax}}\right.$ to $\left.+\mathrm{V}_{\mathrm{Tmax}}\right)[9]$. 
This article is author's version published in the Journal of Magnetism and Magnetic Materials, 398 (2016) 101-108.

Final published version of this paper is available at http://dx.doi.org/10.1016/i.jmmm.2015.09.029

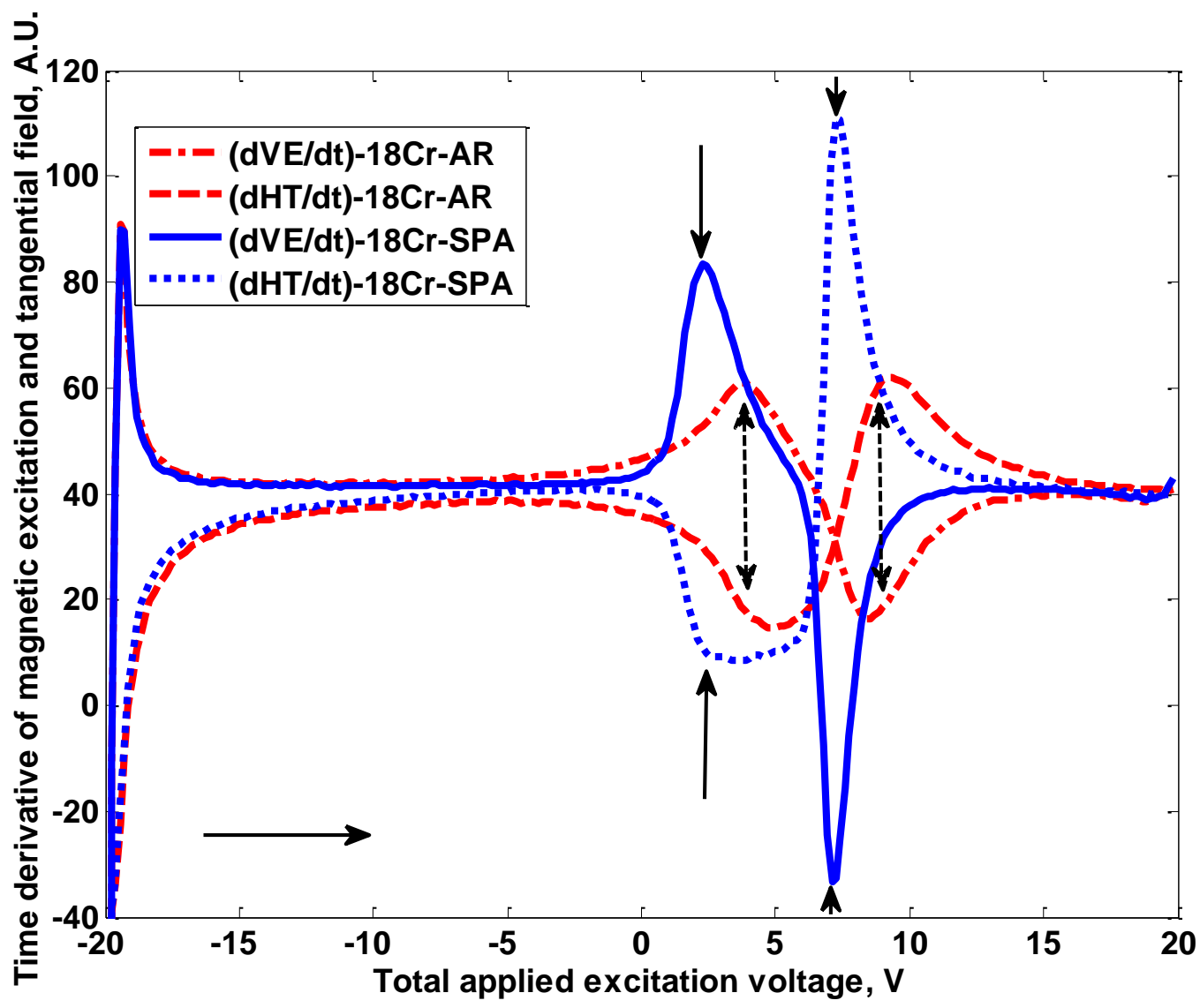

Figure 8. Superimposed DAME $\left(d V_{E} / d t\right)$ and DATF $\left(d H_{T} / d t\right)$ profiles as a function of total applied excitation voltage $\left(\mathrm{V}_{\mathrm{T}}\right)$ measured with $18 \mathrm{CrNiMo5}$ steel $\mathrm{AR}$ and SPA samples for half the magnetisation cycle $\left(-\mathrm{V}_{T_{\max }}\right.$ to $\left.+\mathrm{V}_{T_{\max }}\right)$. (TF denotes the tangential field, $\left(d H_{T} / d t\right)$ and $\mathrm{ME}$ denotes the magnetic excitation voltage, $\left.\left(d V_{E} / d t\right)\right)$. 
This article is author's version published in the Journal of Magnetism and Magnetic Materials, 398 (2016) 101-108.

Final published version of this paper is available at http://dx.doi.org/10.1016/i.jmmm.2015.09.029

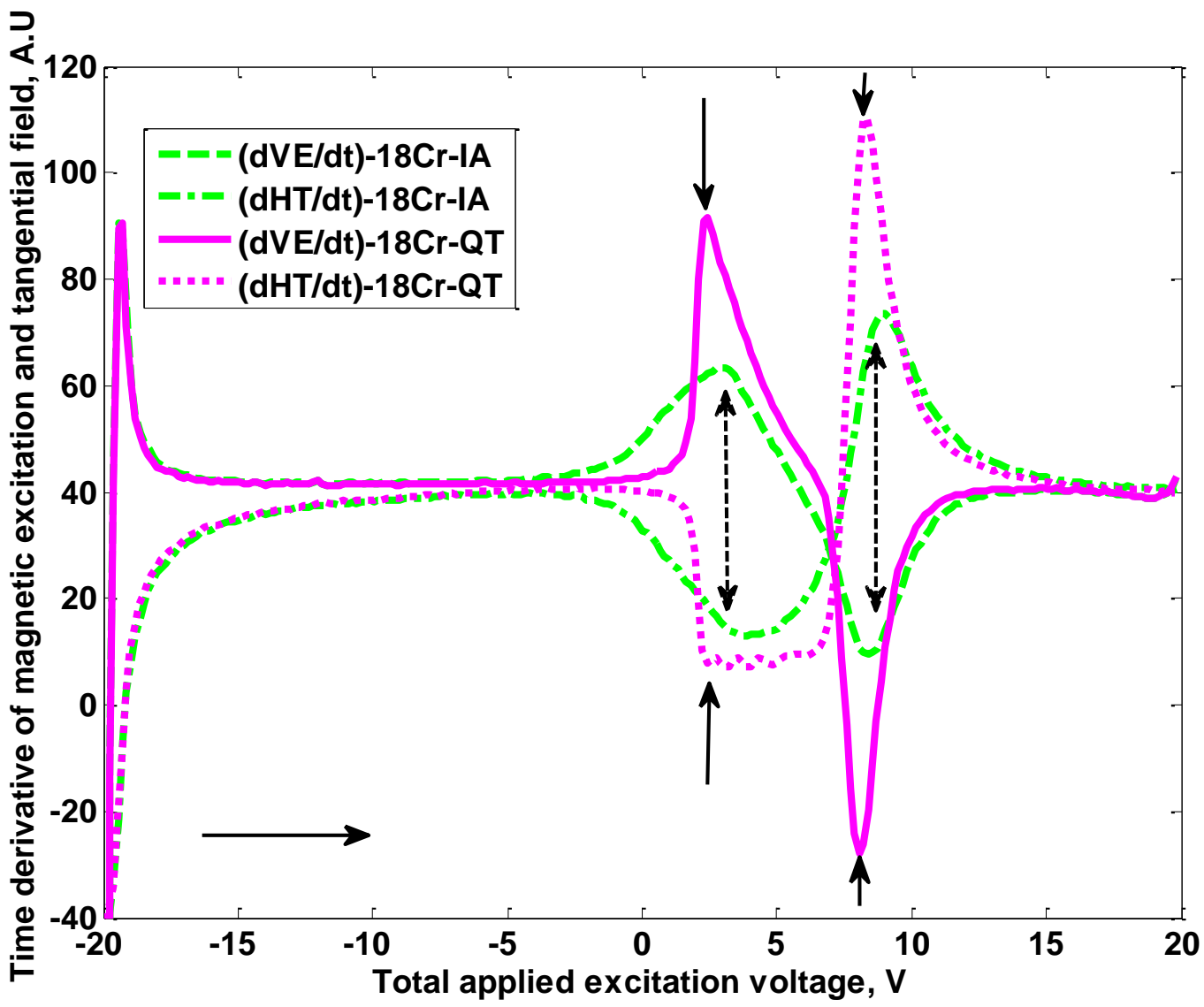

Figure 9. Superimposed DAME $\left(d V_{E} / d t\right)$ and DATF $\left(d H_{T} / d t\right)$ profiles as a function of total applied excitation voltage $\left(\mathrm{V}_{\mathrm{T}}\right)$ measured with $18 \mathrm{CrNiMo5}$ steel IA and QT samples for half the magnetisation cycle $\left(-\mathrm{V}_{T \max }\right.$ to $\left.+\mathrm{V}_{T \max }\right)$. (TF denotes the tangential field, $\left(d H_{T} / d t\right)$ and $\mathrm{ME}$ denotes the magnetic excitation voltage, $\left.\left(d V_{E} / d t\right)\right)$. 
This article is author's version published in the Journal of Magnetism and Magnetic Materials, 398 (2016) 101-108.

Final published version of this paper is available at http://dx.doi.org/10.1016/i.jmmm.2015.09.029

Figures in black and white for print publication

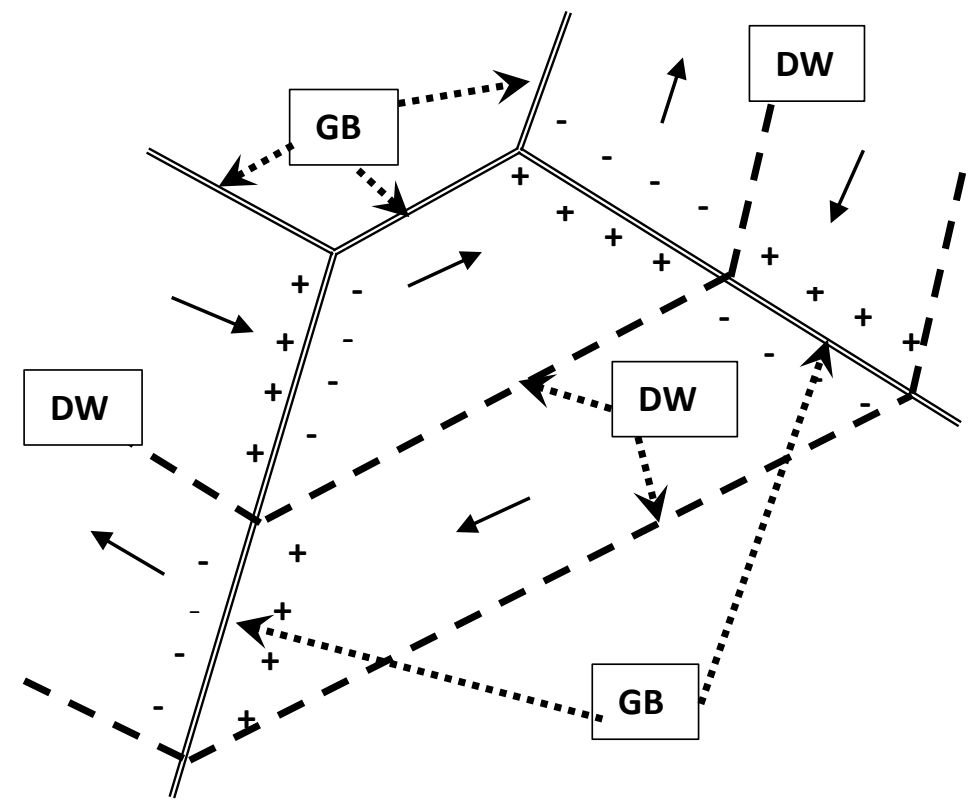

(a)

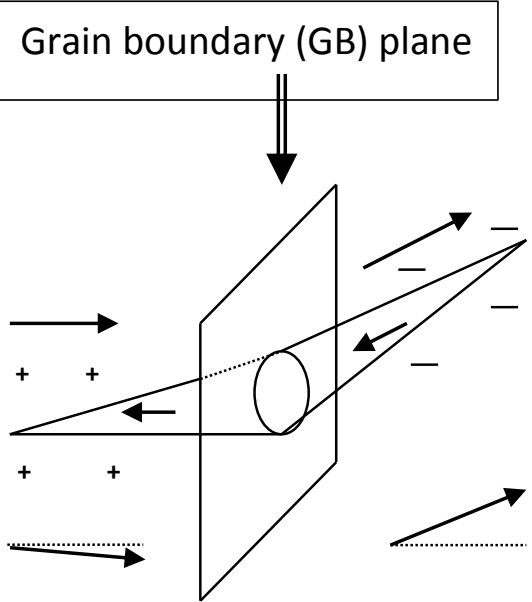

(b)

Figure 1. (a) Multi-domain structure in a thermally demagnetized polycrystalline material with magnetic free poles at the grain boundary (GB) interface and (b) Schematic of formation of reverse spike domain structure at a grain boundary (GB) to reduce the boundary surface magnetic free pole density. (DW refers to Domain Wall). 
This article is author's version published in the Journal of Magnetism and Magnetic Materials, 398 (2016) 101-108.

Final published version of this paper is available at http://dx.doi.org/10.1016/i.jmmm.2015.09.029

\section{DW}
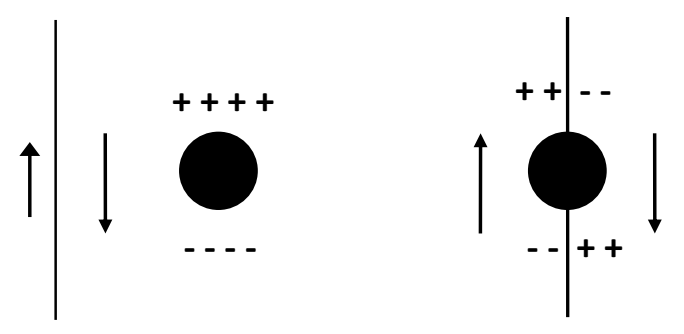

$H_{\text {id }}$

$\mathrm{H}_{\text {id }} / 2$

(a)

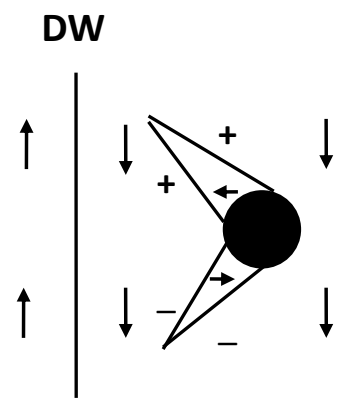

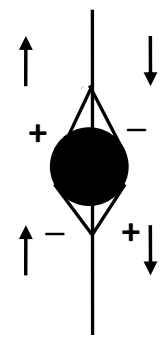

$\mathrm{H}_{\mathrm{id}} / 2$

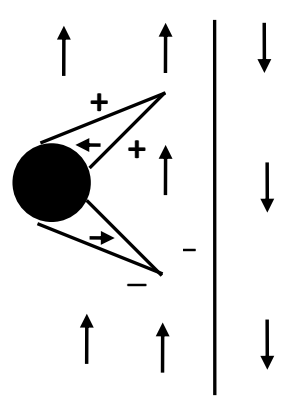

$H_{\text {id }}$

$H_{\text {id }}$<smiles>[CH]=C</smiles>

Direction of magnetization

(b) 
This article is author's version published in the Journal of Magnetism and Magnetic Materials, 398 (2016) 101-108.

Final published version of this paper is available at http://dx.doi.org/10.1016/i.jmmm.2015.09.029

Figure 2. Schematic of interaction of $180^{\circ}$ domain wall with inclusion / precipitate, (a) without closure domain and (b) with closure domain resulting in redistribution of magnetic free poles at the interface and hence reduction in internal demagnetizing field $\left(\mathrm{H}_{\mathrm{id}}\right)$.

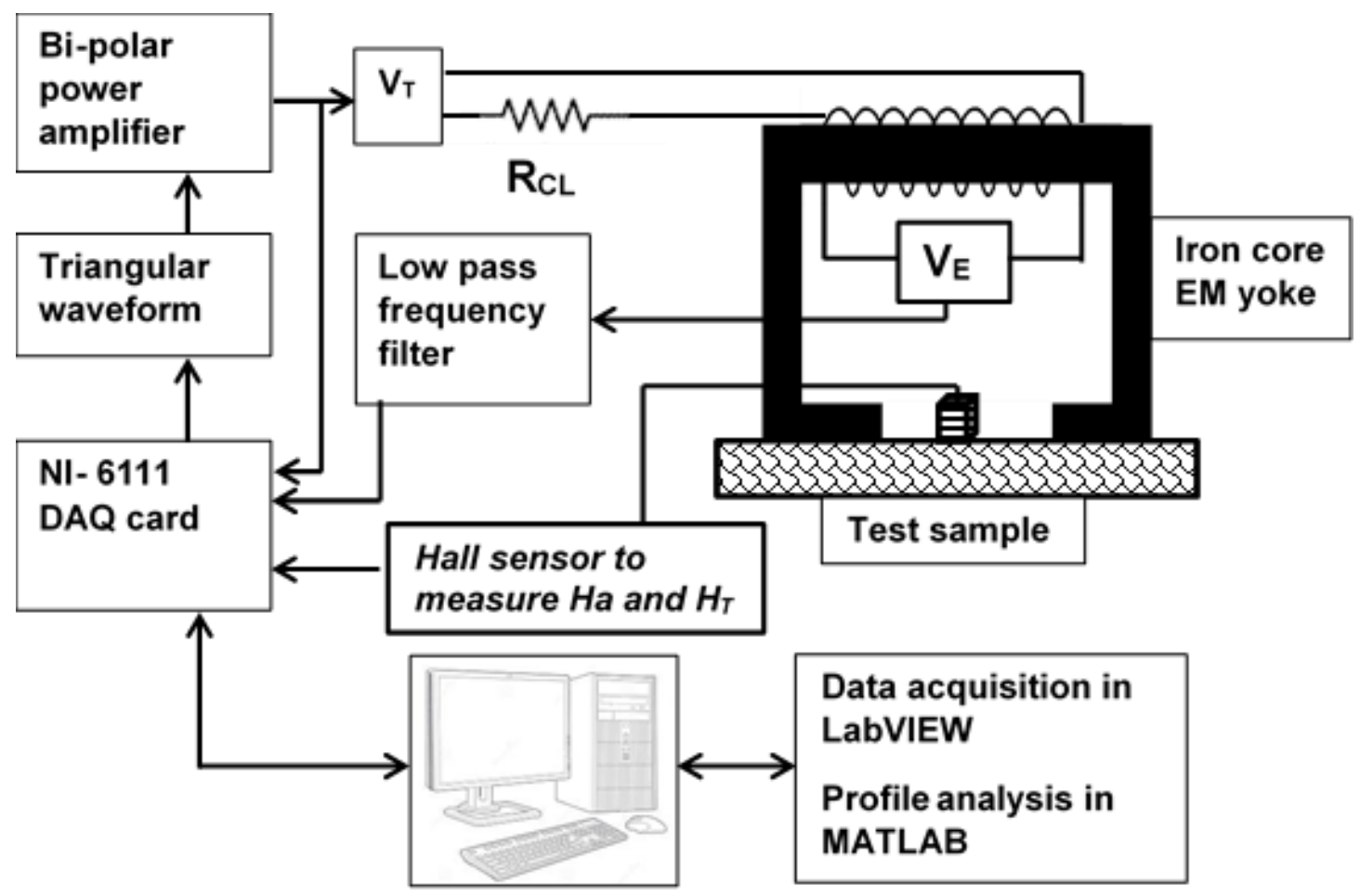

Figure 3. Schematic experimental set-up used for acquiring and analysing distortion of magnetic field strength and magnetic excitation voltage. 
This article is author's version published in the Journal of Magnetism and Magnetic Materials, 398 (2016) 101-108.

Final published version of this paper is available at http://dx.doi.org/10.1016/i.jmmm.2015.09.029

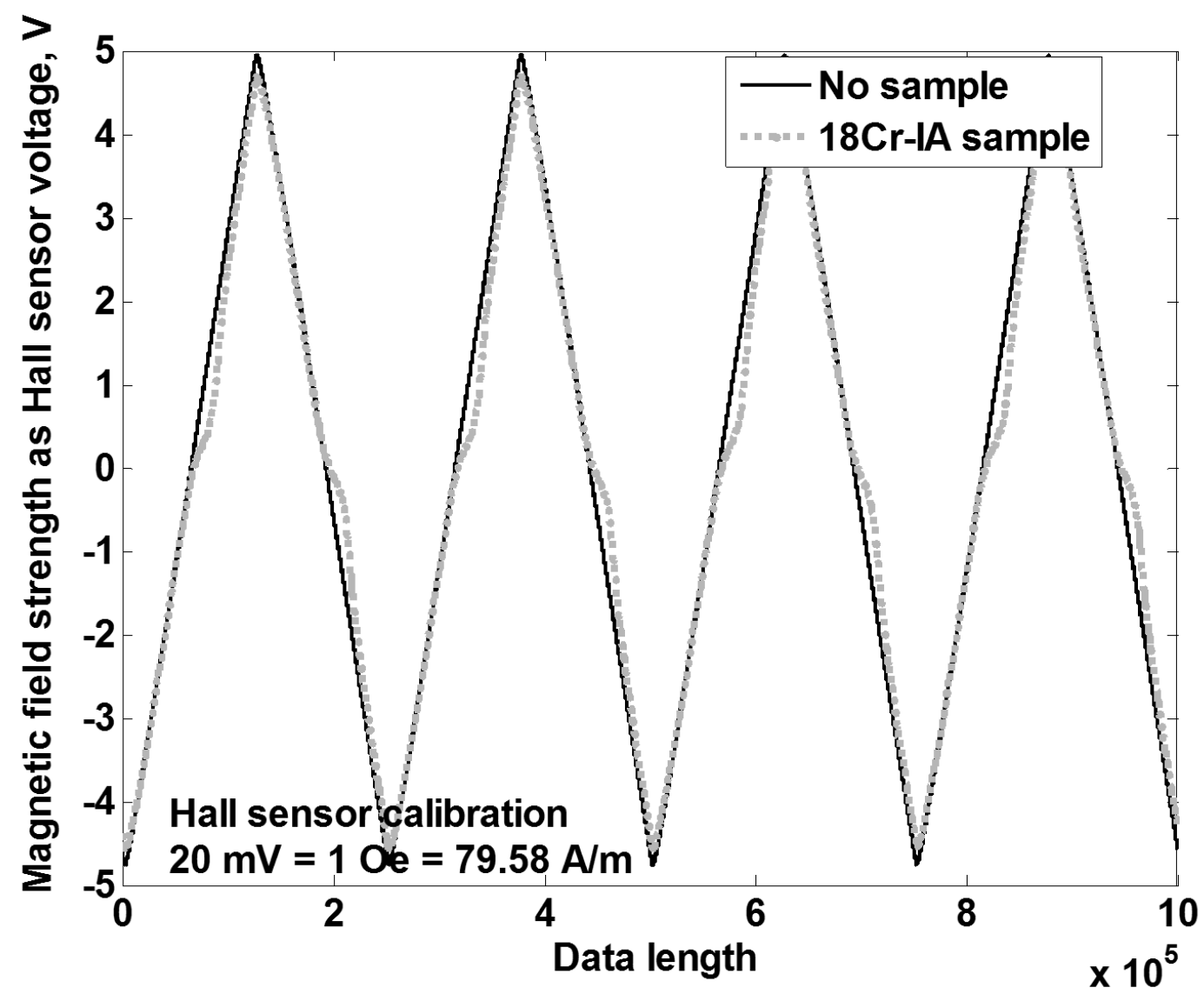

Figure 4. Typical variations in applied magnetic field $\left(\mathrm{H}_{\mathrm{a}}\right)$ measured without any sample and the tangential magnetic field $\left(\mathrm{H}_{\mathrm{T}}\right)$ measured on an isothermally annealed $(\mathrm{IA}) 18 \mathrm{CrNiMo5}$ steel bar sample are shown for a total duration of $10 \mathrm{~s}$ over 4 cycles of magnetisation. The nonlinear distortion in tangential magnetic field $\left(\mathrm{H}_{\mathrm{T}}\right)$ with IA sample can be noticed clearly. The magnetic field strength is shown as Hall sensor voltage which is calibrated to give $20 \mathrm{mV}$ for 1 Oe $(79.58 \mathrm{~A} / \mathrm{m})$. 
This article is author's version published in the Journal of Magnetism and Magnetic Materials, 398 (2016) 101-108.

Final published version of this paper is available at http://dx.doi.org/10.1016/i.jmmm.2015.09.029

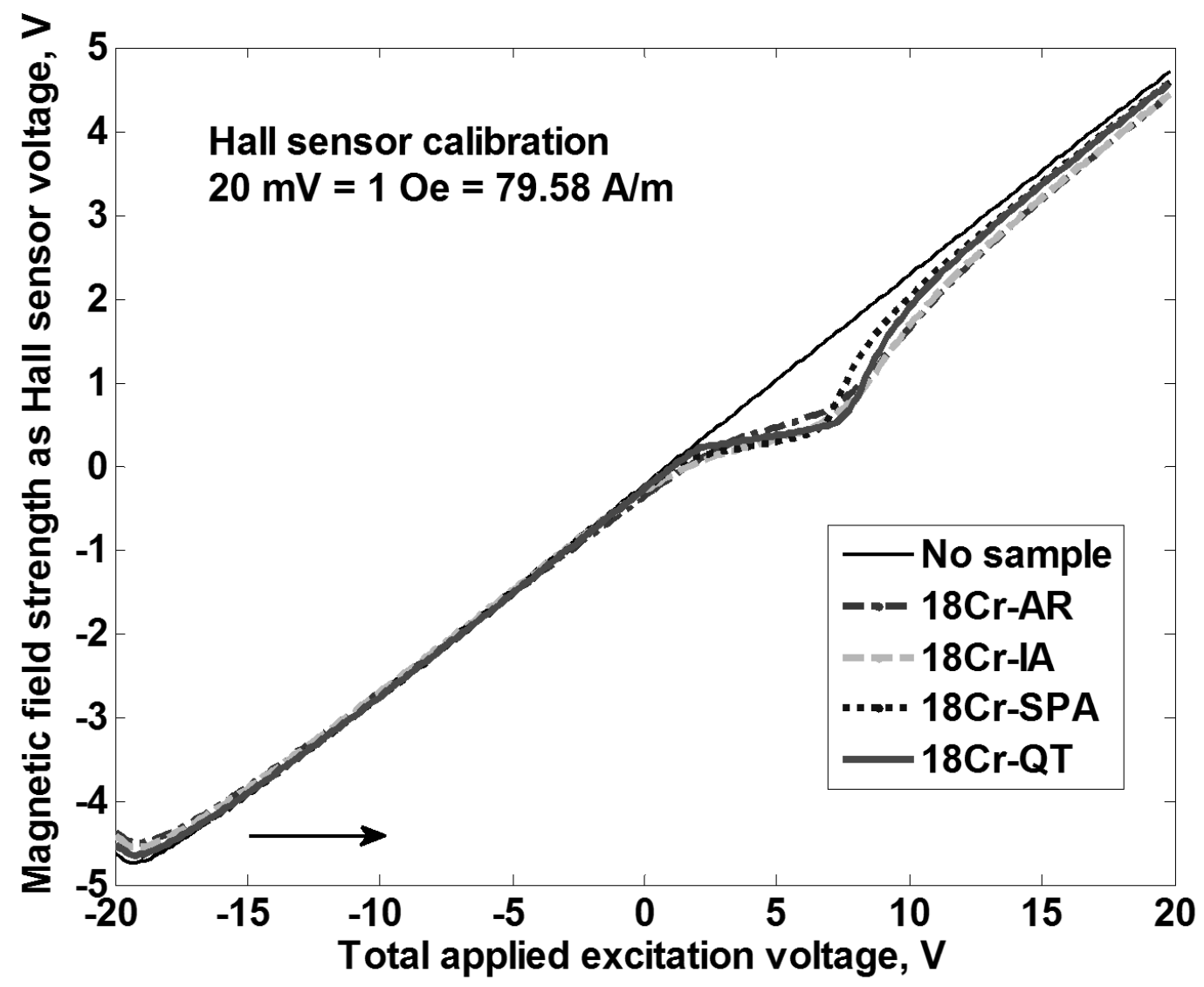

Figure 5. Variations in average applied magnetic field $\left(\mathrm{H}_{\mathrm{a}}\right)$ measured without any sample and average tangential magnetic field $\left(\mathrm{H}_{\mathrm{T}}\right)$ measured with different heat-treated $18 \mathrm{CrNiMo5}$ steel bar samples as a function of total applied voltage $\left(\mathrm{V}_{\mathrm{T}}\right)$ for half the magnetisation cycle $\left(-\mathrm{V}_{\mathrm{Tmax}}\right.$ to $+\mathrm{V}_{\left.T_{\max }\right)}$. The magnetic field strength is shown as Hall sensor voltage which is calibrated to give $20 \mathrm{mV}$ for 1 Oe $(79.58 \mathrm{~A} / \mathrm{m})$. 
This article is author's version published in the Journal of Magnetism and Magnetic Materials, 398 (2016) 101-108.

Final published version of this paper is available at http://dx.doi.org/10.1016/i.jmmm.2015.09.029

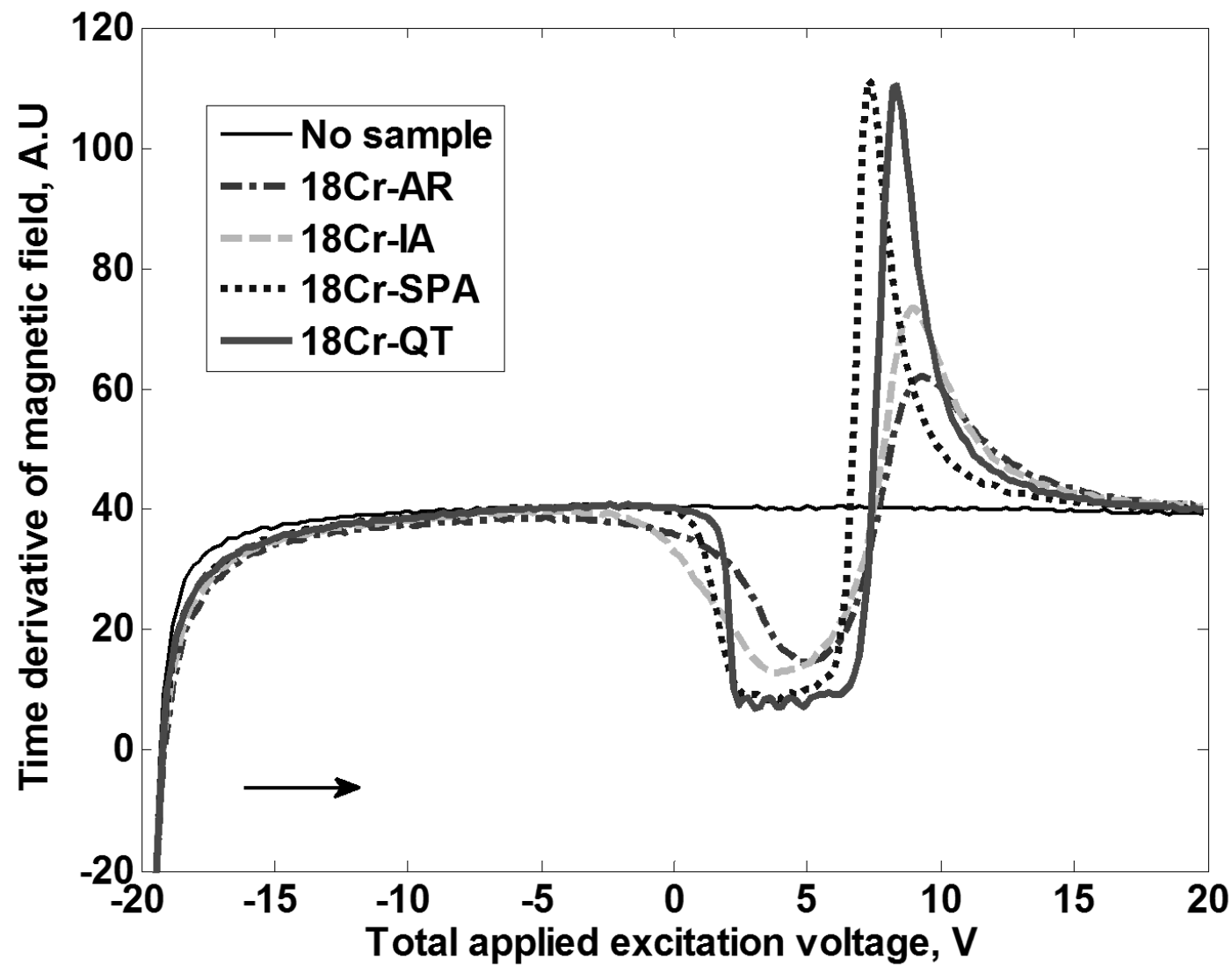

Figure 6. Variations in time derivative of the magnetic field as a function of total applied excitation voltage $\left(\mathrm{V}_{\mathrm{T}}\right)$ measured without any sample $\left(d H_{a} / d t\right)$ and with different heat-treated $18 \mathrm{CrNiMo5}$ steel bar samples $\left(d H_{T} / d t\right)$ for half the magnetisation cycle $\left(-\mathrm{V}_{\mathrm{Tmax}}\right.$ to $\left.+\mathrm{V}_{\mathrm{Tmax}}\right)$. 
This article is author's version published in the Journal of Magnetism and Magnetic Materials, 398 (2016) 101-108.

Final published version of this paper is available at http://dx.doi.org/10.1016/i.jmmm.2015.09.029

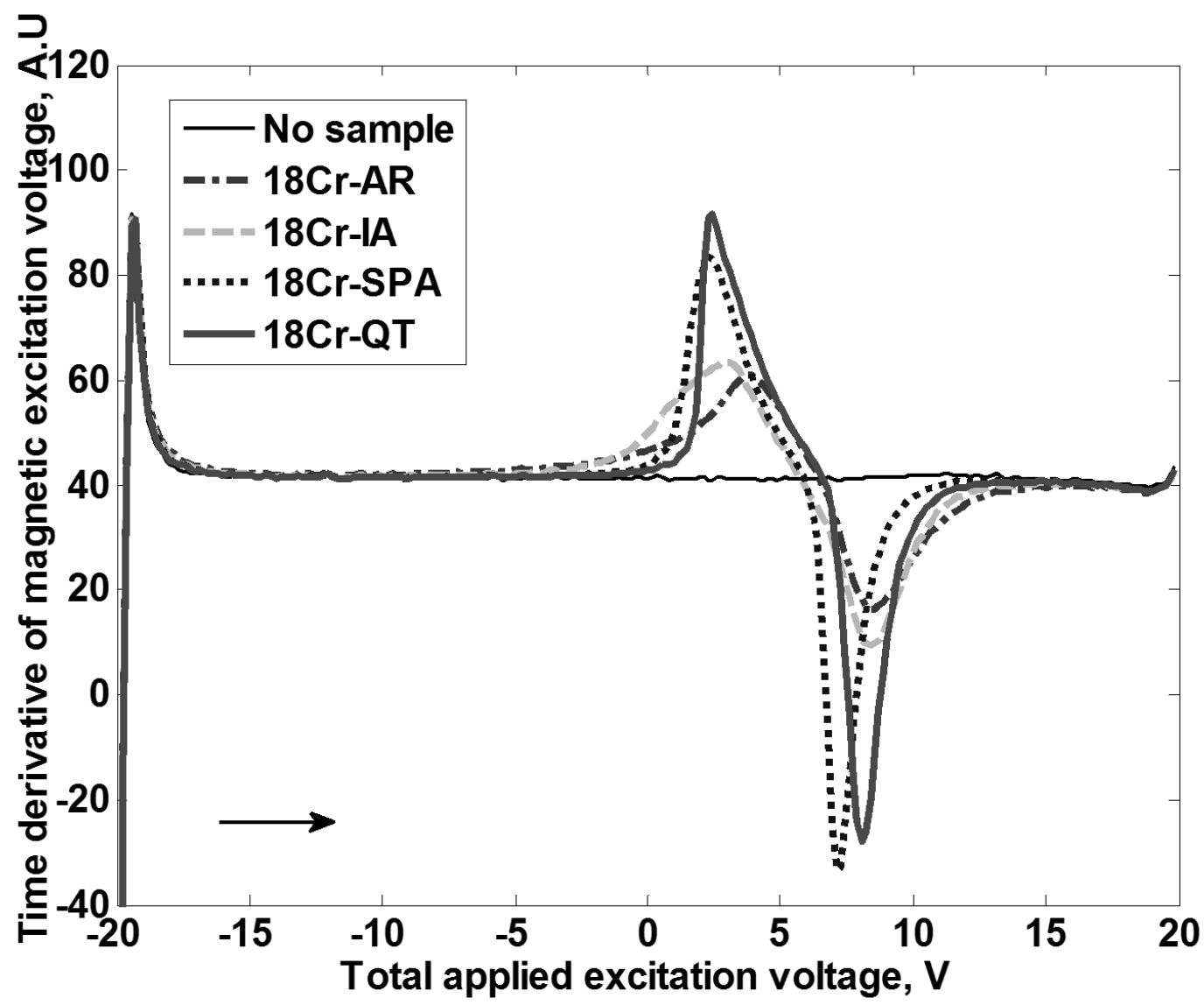

Figure 7. Variations in time derivative of the magnetic excitation voltage across the EM yoke $\left(d V_{E} / d t\right)$ as a function of total applied excitation voltage $\left(\mathrm{V}_{\mathrm{T}}\right)$ measured without any sample and with different heat-treated $18 \mathrm{CrNiMo5}$ steel bar samples for half the magnetisation cycle $\left(-\mathrm{V}_{\mathrm{Tmax}}\right.$ to $\left.+\mathrm{V}_{\mathrm{Tmax}}\right)[9]$. 
This article is author's version published in the Journal of Magnetism and Magnetic Materials, 398 (2016) 101-108.

Final published version of this paper is available at http://dx.doi.org/10.1016/i.jmmm.2015.09.029

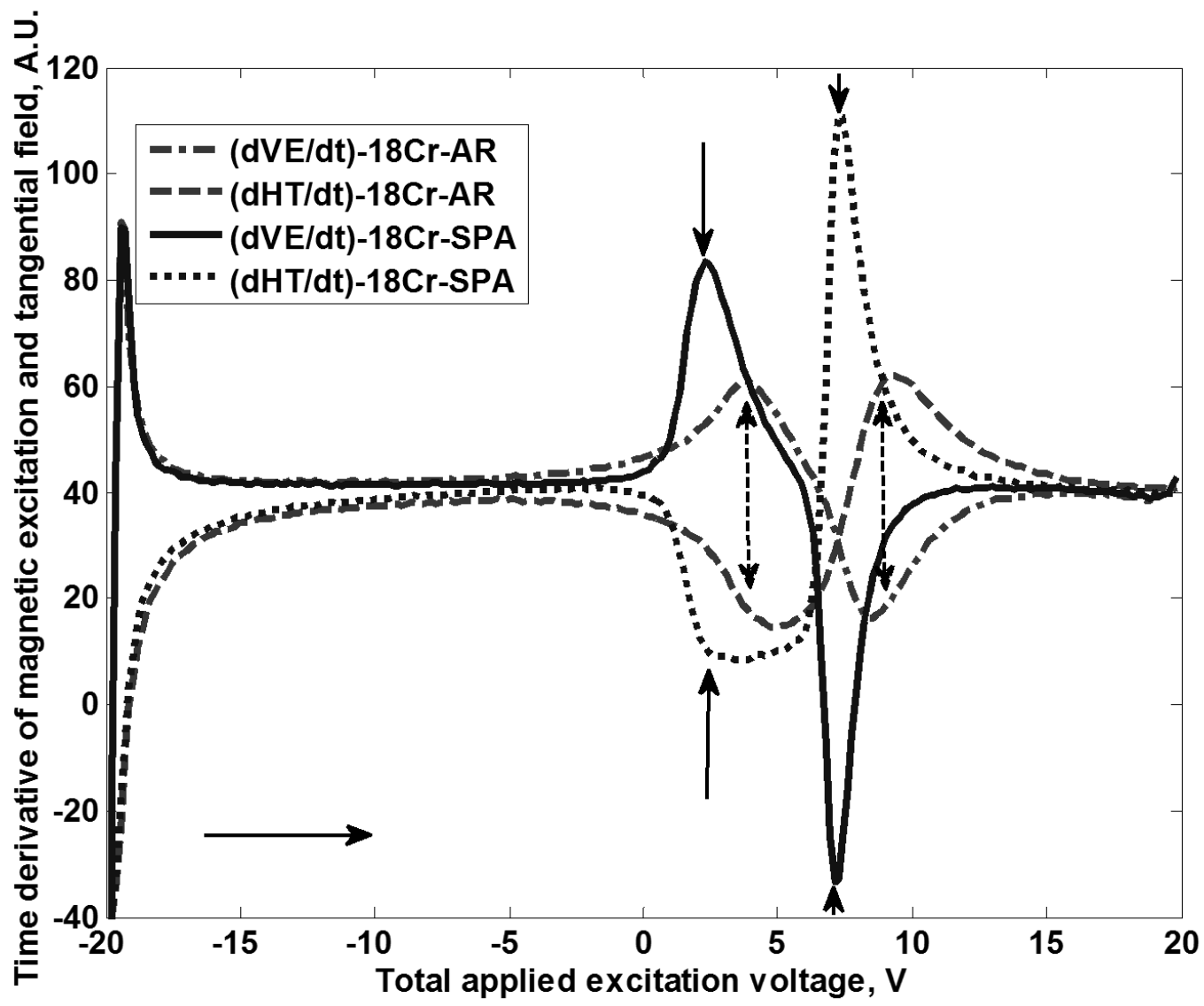

Figure 8. Superimposed DAME $\left(d V_{E} / d t\right)$ and DATF $\left(d H_{T} / d t\right)$ profiles as a function of total applied excitation voltage $\left(\mathrm{V}_{\mathrm{T}}\right)$ measured with $18 \mathrm{CrNiMo5}$ steel $\mathrm{AR}$ and SPA samples for half the magnetisation cycle $\left(-\mathrm{V}_{T_{\max }}\right.$ to $\left.+\mathrm{V}_{T_{\max }}\right)$. (TF denotes the tangential field, $\left(d H_{T} / d t\right)$ and $\mathrm{ME}$ denotes the magnetic excitation voltage, $\left.\left(d V_{E} / d t\right)\right)$. 
This article is author's version published in the Journal of Magnetism and Magnetic Materials, 398 (2016) 101-108.

Final published version of this paper is available at http://dx.doi.org/10.1016/i.jmmm.2015.09.029

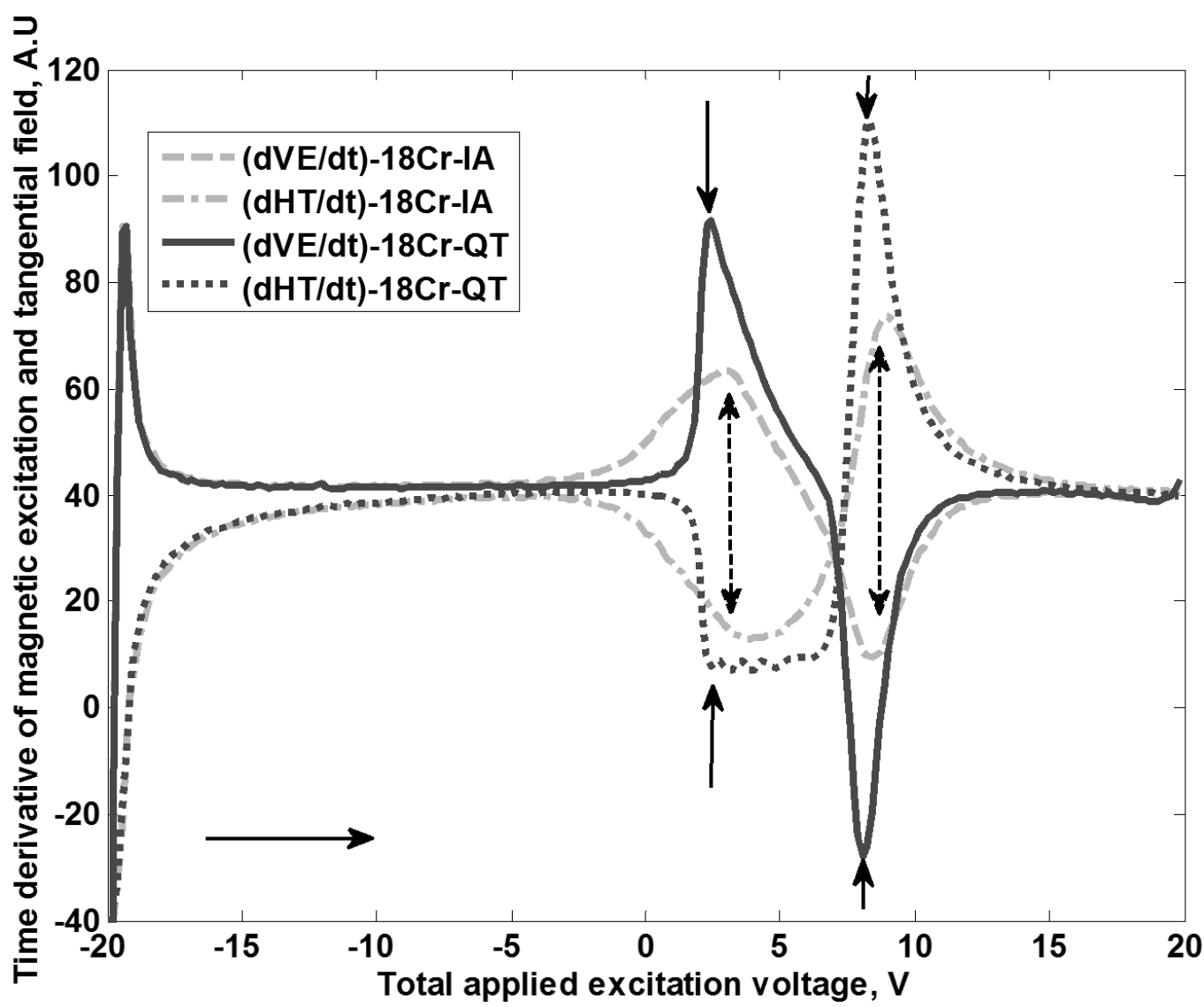

Figure 9. Superimposed DAME $\left(d V_{E} / d t\right)$ and DATF $\left(d H_{T} / d t\right)$ profiles as a function of total applied excitation voltage $\left(\mathrm{V}_{\mathrm{T}}\right)$ measured with $18 \mathrm{CrNiMo5}$ steel IA and QT samples for half the magnetisation cycle $\left(-\mathrm{V}_{T \max }\right.$ to $\left.+\mathrm{V}_{T \max }\right)$. (TF denotes the tangential field, $\left(d H_{T} / d t\right)$ and $\mathrm{ME}$ denotes the magnetic excitation voltage, $\left.\left(d V_{E} / d t\right)\right)$. 